\title{
5. Verfasser, Ort und Zeit.
}

Über die Heimat der Pistis Sophia besteht kein Dissensus unter den Gelehrten. Der ägyptische Ursprung der in Cod. Askewianus vereinigten gnostischen Werke ist nämlich allgemein anerkannt, nicht deswegen, weil die koptische Sprache Leser in Ägypten voraussetzt, sondern als besonderes Kennzeichen gilt die Benutzung des ägyptischen Kalenders in Buch I, da der Aufstieg Jesu auf den 15. Tybi, den Vollmondstag, verlegt wird (S. 3, 25; 4, 20.33). Besonders Buch IV ist stark von spezifisch ägyptischen Ideen durchsetzt.

1. Die Bubastis (- Bast), welche mit der Aphrodite identifiziert wird (S. 268, 4. 36; 269, 31; 270, 21).

2. Die Vorstellung von dem Sonnen- und Mondschiff (S. 262,23 ff.).

3. Der Archon Typhon auf dem Wege der Mitte (S. 270, 6).

4. Die Ariûth, die Äthiopin, ein weiblicher Archon auf dem Wege der Mitte, der ganz schwarz ist (S. 268, 20).

5. Die Vorstellungen von den Fahrten der Seele nach dem Tode und ihre Strafen in den verschiedenen Regionen.

6. Die angeblich unvergänglichen Namen der fünf großen Planeten: Orimûth, Munichunaphôr, Tarpetanûph, Chôsi, Chônbal (S. 264, 33 f.).

7. Die barbarischen Namen wie z. B. $\beta a \ddot{v} \chi \omega \omega \omega \chi$ (S. 264, $11 ; 283,22)$, die an die griechisch-ägyptischen Zauberpapyri erinnern.

8. Die Bekämpfung einer gnostischen Sekte, die obszönen Riten beim Abendmahl fröhnte (S. 282, 33 ff.). Diese libertinistischen Gnostiker traf Epiphanius in Ägypten an und gab über sie in h. 26 Nachricht.

Was das Alter des gnostischen Werkes anbetrifft, so scheint mir die Datierung von Harnack ${ }^{1}$ auf das 3. Jahrh., näher in dessen zweite Hälfte noch immer der Wahrheit am nächsten zu kommen. Unter den von ihm gemachten Beobachtungen möchte ich folgende unterstreichen:

1. Der Verfasser hat in einer Zeit geschrieben, wo die Christen noch gesetzlich verfolgt worden. Ausdrücklich

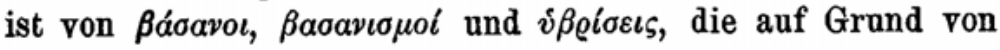

1 Über das gnostische Buch Pistis Sophia, TU VII, 2, S. $95 \mathrm{ff}$. 
Gesetzen erfolgen, die Rede (S. 202, 24 f.), ebenso von Leiden in den $\delta i \omega \gamma \mu o i$ S. 8,$9 ; 241,38$, und es wird bemerkt, daß noch zahlreich sind die, welche sie um des Namens Christi willen verfolgen und peinigen (S. 202, $32 \mathrm{f}$.).

2. Charakteristisch ist die Stellung $\mathrm{zu}$ den christlichen Urkunden A. und N. T.s. Hatte der Gnostizismus der älteren Epoche das A. T. als Urkunde des bösen Judengottes, resp. des Demiurgen rundweg verworfen, so zeigen sich in der P. S. nur Nachwehen dieses Kampfes. Denn zwar sollen nach S. 259, $27 \mathrm{f}$. die Propheten Diener der Archonten der Aeonen gewesen sein, indem diese mit ihnen gesprochen haben; infolgedessen konnten ihre Seelen noch nicht in das Lichtreich eingehen -, aber auf der andern Seite heißt es, daß die in dem Propheten Jesaias befindliche Kraft Jesu über ihn prophezeit (S. 19, 25. 33; 20,4) hat; insbesondere gilt David als der Inhaber der Lichtkraft Jesu, ebenso Salomo. ${ }^{1}$ So hat dieser Gnostizismus die alttest. Urkunden als Weissagungsbuch auf Christus in Übereinstimmung mit dem gemeinchristlichen Glauben anerkannt. Desgleichen beruht der evangelische Stoff wesentlich auf den vier kirchlichen Evangelien; an dem Texte selbst ist keine Veränderung vorgenommen, nur die Worte sind gnostisch interpretiert worden. Der Spruch des Paulus Roem. 13, 7 wird in argem Anachronismus als ein Wort des Herrn durch dessen Mund bezeichnet (S. 214, $30 \mathrm{f}$.).

3. Spielten in der altchristlichen Missionspraxis die Dämonenaustreibungen und Heilungswunder an Lahmen, Blinden, Tauben und Stummen in Nachfolge Jesu eine große Rolle, so will die gnostische Propaganda nicht ganz auf sie verzichten, aber das Mysterium der Totenauferweckung und Krankenheilung darf nur in Ausnahmefällen von den Missionaren ausgeübt werden; vor allem darf es nicht an andere übertragen werden, denn die damit verbundenen Anrufungen gehören der Archontenwelt an, ${ }^{2}$ sind also heidnischen Ursprungs.

1 Die Oden Salomos sind auf eine Linie mit den Psalmen Davids gestellt. Sie sind dem Verfasser aus dem Gebrauche der christlichen Gemeinden bekannt. Deshalb war es $\mathrm{m}$. E. eine Verirrang der Literarkritik, die von R. Harris entdeckten Oden als gnostische Fabrikate erweisen zu wollen.

2 Den Getauften ist daher die Anrufung des Namens der Archonten und ihrer Engel verboten (Kopt.-gnost. Schriften I, S. 305, 30). 
4. Das gesamte Christentum ist vollständig in einen Mysterienkult umgewandelt. Die BuB- und Vergebungsfragen beherrschen das ganze Buch, und die Sakramente der Sündenvergebung und Entsühnung spielen eine große Rolle. Neben die Mysterien der Taufen, die die Menschen beim Initiationsakt von der Materie, d. h. von der Sünde reinigen und von der Herrschaft der Archonten befreien, treten die Mysterien der höheren Grade, welche den rückfälligen getauften Sündern bis zar äuBersten Grenze die Sünden nicht anrechnen, sobald sich wieder Spuren von Reue zeigen, ja die selbst den Missetätern im Fegefeuer zugute kommen können. Mit einer Kasuistik sondergleichen werden alle nur erdenklichen Möglichkeiten besprochen, eine Kasuistik, die für das 2. Jahrh. ganz unerhört ist. Bei aller Latitude in der Bußpraxis ist man doch nicht in das libertinistische Fahrwasser geraten, sondern ein hoher Grad von sittlichem Ernst macht sich in dem Laster- und Tugendkatalog bemerkbar. Und mit diesen Fragen der Sündenvergebung ist die Frage nach den verschiedenen Stufen der Seligkeit aufs engste verbunden. Die größte Sorge ist die, mit Hilfe der Mysterien den höchsten Platz im Lichtreiche zu erlangen. Die früheren einfachen Mysterien genügten nicht mehr, und so hat man in späterer Zeit neue Mysterien erfunden. Das ist $\mathrm{m}$. E. ein deutliches Zeichen der Dekadenze.

Aber wer trotz alledem die P. S. dem 2. Jahrh. zuweisen will, den möchte ich darauf hinweisen, daß das Buch I-III auf eine ältere Phase des Systems, bzw. auf eine ältere Literatur der Sekte hinweist und damit indirekt die Entstehung in einer späteren Zeit zu erkennen gibt. Schon die einleitenden Bemerkungen über Unterredungen Jesu mit den Jüngern in den 11 Jahren nach der Auferstehung tragen keinen rein fingierten Charakter, sondern verraten deutlich, da $B$ aus der früheren Zeit schriftliche Urkunden über Offenbarungen Jesu vorhanden gewesen sind. Da hören wir ferner unmittelbar vor der Erzählung des Mythus von der P. S. aus dem Munde der Maria die Worte: „Mein Herr, ich habe Dich einst sagen hören: Die Pistis Sophia ist selbst yon den 24 Emanationen" (S. 31, 6f.). Eine derartige Aussage Jesu finden wir in den vorhergehenden Ausführungen nicht; 
überhaupt weist der Ausdruck „einst“ auf ältere schriftliche Quellen hin; denn alle alt- und neutestamentlichen Zitate werden stets mit "einst" eingeführt. Daraus geht mit Evidenz hervor, daß der Mythus von der Sophia dem Verfasser in einer schriftlichen Überlieferung vorlag. - Ferner fügt Jesus bei der Erwähnung des Jaldabaoth S. 33, 20 hinzu: "von dem ich zu euch oftmals geredet habe". Nun wird an dieser Stelle Jaldabaoth zum ersten Male erwähnt, deshalb muß das "of tma Is" sich auf frühere Schilderungen beziehen, die anßerhalb der P. S. liegen. Jaldabaoth war ja bei einer bestimmten Gruppe von Gnostikern eine ganz bekannte Figur, da er gewöhnlich als Sohn der Sophia-Prunikos oder der Barbelo erscheint und zugleich als Inhaber des siebten Himmels, deshalb auch der Weltschöpfer. In der P. S. dagegen ist er dieser hohen Stellung verlustig gegangen; er ist jetzt in das Chaos dislociert und waltet als Archon mit Löwengesicht daselbst mit seinen Feuer-, Pech- und Schwefelmeeren seines furchtbaren Strafamtes. ${ }^{1}$ Wiederum ein Zeichen späterer Zeit!

Bei anderer Gelegenheit bemerkt Jesus, daß er gewisse Fragen ein andermal beantwortet hätte, aber jetzt von nenem darüber sprechen wolle (S. 201, 24; 203, 1; 204, 12). ${ }^{2}$ Auch sonst verweist Jesus auf Aussagen von einem andern Male (S. 136, 35; 137, 2. 11; 138, 3; 148, 36; 149, 4; 176, 17), ohne zu bemerken, daß er noch einmal darauf zurückkommen wolle. Er setzt also diese Ausführungen als irgendwo anders gegeben voraus.

Und nun die Hauptsache! Auf S. 179, 23. $33 \mathrm{f}$. und S. 258, 14 f. 33 wird auf zwei (große) Bücher Jê̂, resp. Bücher des Jeû verwiesen. Es heißt an erster Stelle: „Dies sind die drei Erbteile des Lichtreiches. Die Mysterien dieser drei Erbteile des Lichtes sind sehr zahlreich; ihr werdet sie in den beiden groben Büchern des Jeû finden, aber ich werde euch geben und euch sagen die großen Mysterien jedes Erbteiles, diese, welche höher als jeder Ort sind, d. h. die Häupter gemä $B$ jedem Orte und gemäß jeder Ordnung, welche das ganze Menschengeschlecht in die höheren

- 1 Denkt dabei der Verfasser an die Schilderungen in Buch IV?

2 Über diesen Punkt s. 0. S. XLVIIf. 
Örter gemäß dem Raume des Erbes führen werden. Die übrigen niederen Mysterien nun habt ihr nicht nötig, sondern ihr werdet sie in den beiden Büchern des Jế finden, die Henoch geschrieben hat, während ich mit ihm aus dem Baumeder Erkenntnis und aus dem Baumedes Lebens in dem Paradiese des Adam sprach. Jetzt nun, wenn ich euch die ganze Ausbreitung auseinandergesetzt haben werde, werde ich euch geben und euch sagen die großen Mysterien der drei Erbteile meines Reiches, d. h. die Hänpter der Mysterien etc." Die zweite Stelle lautet: „Jetzt nun wegen der Sünder habe ich mich abgemüht und bin in die Welt gekommen, damit ich sie errette, denn selbst für die Gerechten, die niemals etwas Böses getan und die überhanpt nicht gesündigt haben, ist es notwendig, daß sie die Mysterien finden, die in den Büchern des Jeû, die ich Henoch im Paradiese habe schreiben lassen, indem ich mit ihm aus dem Baume der Erkenntnis und aus dem Baume des Lebens redete, und ich lieb ihn sie a uf den Felsen Ararad niederlegen und stellte den Archon Kalapatauroth, der über das Siebengestirn, auf dessen Haupt der FuB des Jê̂, und der alle Aeonen und Heimarmenen umgibt, jenen Archon stellte ich auf als Wächter über die Bücher des Jeû wegen der Sintflut, und damit keiner von den Archonten auf sie neidisch sei und sievernichte-diese, welche ich euch geben werde, wenn ich each die Darlegung des Alls gesagt haben werde."

Ich hatte in meinen Untersuchungen za den von mir aus dem Codex Brucianus herausgegebenen gnostischen Schriften (TU VIII, 1. 2, S. $480 \mathrm{ff}$.) die These aufgestellt, daß die in der P. S. genannten zwei Bücher Jeû identisch seien mit dem ersten großen Werke, aus zwei Büchern bestehend (Kopt.gnost. Schriften, Bd. I, S. 257-329). In der Theol. Litt.-Ztg. 1894, Nr. 7, Kol. $184 \mathrm{f}$. hat Preuschen diese Identifikation verworfen und ebenso Liechtenhan l. c. S. 245 ff., nachdem ich vorher meine These eingehend beleuchtet hatte $(Z$. f. wissensch. Theol. 1894, S. 555 ff.). Ich sehe mich daher ge- 
nötigt, noch einmal die Untersuchung aufzunehmen, und werde dabei die Einwendungen von Liechtenhan berücksichtigen.

Ich gehe wiederum von der ersten Stelle aus. Unmittelbar vorher hatte Jesus davon gesprochen, daß ein jeder an dem Orte verbleibt, bis zu dem er Mysterien empfangen hat, daher die, welche die höheren Mysterien empfangen, in den höheren Örtern bleiben werden, und die, welche die niederen Mysterien empfangen, in den niederen Örtern verbleiben. Bei diesen niederen und höheren Örtern handelt es sich um die drei Erbteile des Lichtes, die wieder in eine Reihe von Örtlichkeiten zerfallen; dementsprechend hat jeder Erbteil wieder eine Reihe von Mysterien, und je nach dem Grade dieser Mysterien wird der Inhaber die dazu passenden Örtlichkeiten in Besitz nehmen und König im 1000 jährigen Reiche, resp. bei der $\sigma v \nu \tau \varepsilon \hat{\lambda \varepsilon l \alpha}$ dieses Aeons an dem betreffenden Orte im Lichtreiche sein. Die drei Erbteile entsprechen den Örtern der drei höchsten Mysterien: den Mysterien der $3 \chi \omega \varrho \eta ́ \eta \alpha \tau \alpha,{ }^{1}$ des 1. Mysteriums und des Unaussprechlichen. Nun heißt es: "ihr werdet sie in den beiden großen Büchern des Jeû finden", und unmittelbar darauf: "aber ich werde euch geben und euch die großen Mysterien jedes Erbteils sagen". Diese beiden Sätze widersprechen sich doch ohne weiteres und noch viel mehr, wenn es nachher heißt: „die übrigen niederen Mysterien habt ihr nicht nötig, sondern ihr werdet sie in den beiden Büchern des Jeû finden". Noch verdächtiger wird der Satz, wenn bei der ersten Erwähnung nur allgemein von den beiden großen Büchern des Jeû die Rede ist, bei der zweiten ihre Entstehung näher beschrieben wird; man hätte doch sicherlich das Umgekehrte erwartet. Daher muß m. E. der erste Satz als interpoliert getilgt werden. ${ }^{2}$ Liechtenhan will den Sinn der Stelle dahin interpretieren, daß die geringen Mysterien unnötig sind, weil man die großen in den Büchern Jeû finden

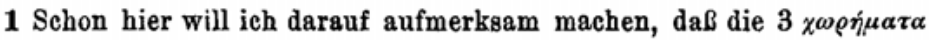
auch in Jeû II S. 317, 38 aufgeführt werden, aber hier ist noch nichts bekannt von ihrer überragenden Bedeutung im Universum; sie stehen ganz

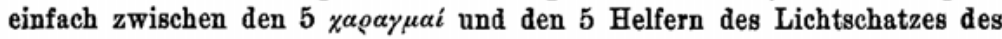

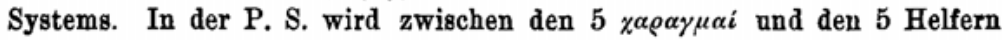
das ${ }_{n}$ große Licht" aufgeführt; s. S. 1, 22; 2, 28; 13, 2f.; vgl. auch S. 160, 17 f.

2 Vielleicht war am Rande eine Bemerkung gemacht und ist diese an eine falsche Stelle geraten. 
wird. Freilich hat er selbst das Gefühl, daß diese Erklärung künstlich ist. Und in der Tat wäre in diesem Falle ja die Erwähnung der niederen Mysterien ganz unnötig gewesen, wenn sie doch keine Bedeutung mehr besitzen, und brauchte Jesus nicht besonders betonen, da $B$ er nach der Darlegung des Alls die großen Mysterien der drei Erbteile seines Reiches geben und sagen werde, und dazu die Formen, Typen, Zahlzeichen, Siegel, Antworten, Verteidigungen und Geheimzeichen, die jeder Inhaber kennen muß. Die einzig richtige Erklärung ist $\mathrm{m}$. E. die, daß das "nicht nötig haben" sich auf das "finden" bezieht: "Ihr habt es nicht nötig, sie zu suchen, ebensowenig habe ich es nötig, sie euch speziell zu übermitteln, denn diese niederen Mysterien sind bereits schriftlich aufgezeichnet und deshalb allen zugänglich." Die beiden Bücher des Jeû sind nämlich durch Henoch niedergeschrieben und zwar ihm in die Feder diktiert von Jesus, indem er im Paradiese mit ihm aus dem Baume der Erkenntnis und des Lebens redete. Nicht deutlich ist, was wir unter den niederen Mysterien zu verstehen haben. Sicherlich können sie nicht identisch sein mit jenen niederen Mysterien der drei Erbteile, denn diese niederen Mysterien werden mit den höheren Mysterien als die großen Mysterien der drei Erbteile zusammengefabt. Sie scheinen auch nicht irgendwelche Berechtigungen des Inhabers für bestimmte Rangstufen in der oberen Welt in sich zu schließen.

Nähere Auskunft erhalten wir erst durch die zweite Stelle auf S. 258. Hier ist ausschließlich die Rede von der Tatsache, daB das ganze Menschengeschlecht unter der Knechtschaft der Archonten und damit unter der Herrschaft der Sünde steht. "Deswegen nun habe ich" - so heißt es S. 256, 2 ff. - "gebracht die Schlüssel der Mysterien des Himmelreiches, sonst würde kein Fleisch auf der Welt gerettet werden, denn ohne Mysterien wird niemand in das Lichtreich eingehen, sei es ein Gerechter, sei es ein Sünder. ${ }^{1}$ Deswegen nun also habe ich die Schlüssel der Mysterien in die Welt ge-

1 Vgl. S. 192, 23 ff.: „Selbst wenn ein gerechter Mensch ubberhaupt keine Sünden begangen hat, so kann er unmöglich in das Lichtreich gebracht werden, weil das Zeichen des Reiches der Mysterien nicht mit ihm ist, mit einem Worte es ist nnmöglich, Seelen zu dem Licht zu bringen ohne die Mysterien des Lichtreiches." 
bracht, damit ich löse die Sünder, die an mich glauben und auf mich hören werden, auf daß ich sie löse aus den Banden und den Siegeln der Aeonen der Archonten und sie binde an die Siegel und die Kleider and die Ordnungen des Lichtreiches ... Um der Sünder willen nun habe ich mich diesmal abgemüht und habe ihnen die Mysterien gebracht, damit ich sie von den Aeonen der Archonten löse und sie in die Erbteile des Lichtes binde, nicht nur die Sünder, sondern auch die Gerechten... Deswegen nun habe ich es nicht verborgen, sondern es deutlich ausgerufen, und nicht habe ich die Sünder getrennt, sondern ich habe es ausgerufen und allen Menschen gesagt, Sündern und Gerechten, indem ich sprach: ,Suchet, auf daß ihr findet, klopfet an, auf daß euch geöffinet werde, denn ein jeder, der in Wahrheit sucht, wird finden, und wer anklopft, dem wird geöffnet werden.' Denn ich habe allen Menschen gesagt: ,Sie sollen suchen die Mysterien des Lichtreiches, welche sie reinigen und sie rein machen und sie in das Licht führen werden'" Aber wenn alles auf das Suchen und Finden ankommt, so entsteht die bange Frage, woran ich denn erkennen kann, ob ich bei meinem Suchen die írichtige Lehre gefunden habe, oder ob nicht der Missionar eine Irrlehre vorträgt. Die Verweisung auf das bekannte Agraphon, 'nach Art der Geldwechsler das Gute zu nehmen, das Schlechte zu verwerfen`, oder auf die Naturbeobachtung der Winde wird die Sorge nicht bannen. Diejenigen freilich, welche bereits mit der gnostischen Lehre bekannt sind, können entscheiden, ob die vorgetragenen Ansichten mit der Lehre Jesu übereinstimmen und den Missionar aufnehmen. Die Hauptsache ist, sich bei der Propaganda an die Sünder zu wenden, da der Herr um der Sünder willen in die Welt gekommen ist. In diesem Zusammenhang kommt Jesus auf die Mysterien zu sprechen, die in den Büchern des Jê̂ zu finden sind. Auch hier wird ihre Niederschrift auf Henoch zurückgeführt und als Offenbarungsmittler Jesus selbst bezeichnet. Des näheren wird auch die Geschichte der Überlieferang behandelt, daß sie nämlich auf den Ararat niedergelegt und einem Archon zur Bewachung übergeben seien, um der Vernichtung einerseits durch die Sintflut, anderseits durch die Archonten zu entgehen. Wo nach der Sintflut die 
Bücher aufbewahrt geblieben sind, erfahren wir nicht; es heißt nur, daß Jesus sie $\mathrm{n}$ a $\mathrm{ch}$ der Darlegung des Alls ${ }^{1}$ den Jüngern geben würde. Demzufolge sollen erst die Bücher am Ende der gesamten Offenbarung übergeben sein. Aber wie reimt sich dies mit der anderen Forderung, daß die in den Büchern Jeû geoffenbarten Mysterien von Sündern und Gerechten gefunden werden müssen, also das notwendige Requisit für jeden.. Menschen bilden, der in die gnostische Sekte aufgenommen werden will, resp. mit deren Verkündigung die Gnostiker ihre Adepten in der Welt zu gewinnen suchen!

Können wir nun von hier aus wenigstens den Charakter der Mysterien feststellen? Zunächst ist von niederen Mysterien hier keine Rede, sondern es wird im allgemeinen von Mysterien gesprochen. Wir ersehen nur aus den vorhergehenden Erörterungen, daß es sich um Mysterien des Lichtreiches handelt, welche alle Menschen, d. h. die Sünder sowohl wie die Gerechten reinigen, sie rein machen und in das Licht führen. Schon der Ausdruck "reinigen" ( $(\alpha \vartheta \alpha \varrho i \zeta \varepsilon \varepsilon v)$ deutet nach dem Sprachgebrauch der Kathartik auf einen Kultusakt, durch dessen Applikation Sünden vom Körper abgewaschen werden. Darunter verstand man in damaliger Zeit den Taufritus. Und in der Tat erinnert ja Jesus unmittelbar darauf an das Beispiel Johannes' des Täufers, S. 257, 3 ff.: „Deswegen nun hat Johannes der Täufer über mich prophezeit, indem er sprach: ,Ich zwar habe euch getantt mit Wasser zur Buße zur Vergebung eurer Sünden; der nach mir kommt, ist stärker als ich; dessen Wurfschaufel in seiner Hand ist, und er wird seine Tenne reinigen, die Spreu zwar wird er verbrennen mit unverlöschlichem Feuer, seinen Weizen aber wird er in seine Scheuer sammeln.' Die in Johannes befind-

1 Auf diese letzte Notiz legt Liechtenhan großes Gewicht, daß nämlich die Übergabe der Bücher am Schluß der ganzen Offenbarung erfolgen solle. Nach meiner Zählung kommt dieser Ausdruck "nach Darlegung des Alls“ noch an 21 Stellen vor. Man hat dabei oft den Eindruck, als wenn sich der Verfasser dabei gar nichts denkt, sondern ganz mechanisch den Ausdruck anwendet. Wenn wirklich alles das, was Jesus für diesen Zeitpunkt aufspart, vorgetragen werden sollte, müßten seine Ausführungen noch viele Bände umfassen, um die volle Erkenntnis zu bringen. - Auch bitte ich zu beachten, daß gemäß der 1 . Stelle Jesus die großen Mysterien der 3 Erbteile des Reiches $\mathbf{n}$ a ch der Darlegung des Alls übergeben will, gemäß der 2. Stelle die beiden Bücher Jeû. 
liche Kraft hat über mich prophezeiet, indem sie wuBte, daß ich die Mysterien in die Welt bringen und die Sünden der Sünder, die an mich glauben und auf mich hören werden, reinigen und sie zum reinen Lichte machen und in das Licht führen würde." Hier wird also Jesus mit seinen Mysterien in deutliche Parallele zu der Taufe des Johannes gestellt und als der Sündenreiniger bezeichnet. Diese Sühneriten der Taufen spielten in der gnostischen Kultgemeinde eine groBe Rolle. Denn Maria stellt die Frage S. 217, $5 \mathrm{ff}$.: "Mein Herr, in welchem Typus vergeben denn die Taufen

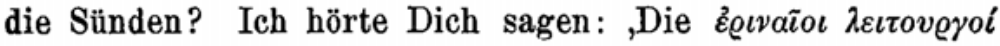
folgen der Seele, indem sie ihr Zeugen sind für alle Sünden, die sie begeht, damit sie sie in den Gerichten überführen. Jetzt nun, mein Herr, wischen die Mysterien der Taufen

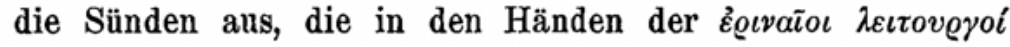
sind, daß sie nämlich ihrer vergessen? Jetzt nun, mein Herr, sage uns den Typus, wie sie Sünden vergeben, aber wir wünschen es bestimmt zu wissen." In der Antwort S. 218, $1 \mathrm{ff}$. wird zunächst beschrieben, wie die Liturgen Zeugen für die sündigenden Seelen sind und wie besonders das ảviím $\mu$ ov $\pi v \varepsilon \tilde{v} \mu \alpha$ dieses Amt verwaltet und darch Siegel die Zahl der Sünden für die späteren Bestrafungen feststellen läßt. Dann heibt es: „Jetzt nun, wer die Mysterien der Taufen empfangen wird, so wird das Mysterium jener zu einem großen, sehr gewaltigen, weisen Feuer, ${ }^{1}$ and es verbrennt die Sünden und geht in die Seele im Verborgenen ein und

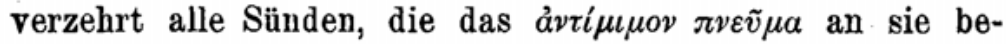
festigt hat. Und wenn es alle Sünden zu reinigen beendet hat, die das $a \partial v \tau$. $\pi v$. an sie befestigt hat, so geht es in den Körper im Verborgenen ein and verfolgt alle Verfolger im Verborgenen und trennt sie nach der Seite des Teiles des Körpers. Denn es verfolgt das $a \dot{v} \tau$. $\pi v$. und die uoĩ $\alpha$ und trennt sie von der Kraft und der Seele und legt sie auf die Seite des Körpers, so daß es das $a v v$. $\pi v$. und die

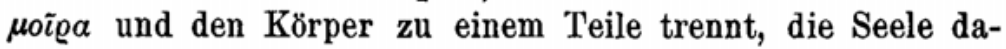
gegen und die Kraft zu einem andern Teile trennt. Das

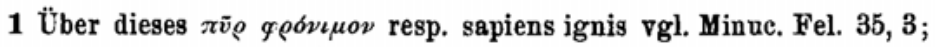
Tertall. apol. 48, 14 f.; Clem. Alex. Paedag. III, 8, 44 n. ö.; Origen. de orat. 29, 15; hom. in Ezech. I, 3. 
Mysterium der Taufe dagegen bleibt in der Mitte von beiden, indem es sie beständig von einander trennt, a uf dab es sie rein macht und sie reinigt, damit sie nicht von der Materie befleckt werden." An der Hand von Lak. 12, 44. $49 \mathrm{ff}$. gibt Maria die gnostische Interpretation (S. 219, 11 ff.): „Das Wort nämlich, das Du gesagt hast: ,Ich bin gekommen, Feuer auf die Erde zu werfen, und was wünsche ich, daß es brenne!' ist dieses, mein Herr: Du hast die Mysterien der Taufen in die Welt gebracht, and was gefällt es Dir, daß sie alle Sünden der Seele verzehren und sie reinigen! Und danach wiederum hast $\mathrm{Du}$ deutlich unterschieden, indem $\mathrm{Du}$ sagtest: ,Ich habe eine Taufe, in ihr zu taufen, und wie werde ich es ertragen, bis daß sie vollendet!, d. h. Du wirst nicht in der Welt bleiben, bis daß die Ta u fen vollendet werden und die vollkommenen Seelen reinigen. Und ferner das Wort, daß $\mathrm{Du}$ zu uns einst gesagt hast: ,Denket ihr, ich sei gekommen, Frieden auf die Erde zu werfen? Nein, sondern Spaltung bin ich gekommen zu werfen, denn von jetzt ab werden fünf in einem Hause sein, drei werden gegen zwei und zwei gegen drei gespalten sein', d. h. Du hast das Mysterium der Taufen in die Welt gebracht, indem es eine Spaltung in den Körpern der Welt bewirkt hat, weil es das $\dot{\alpha} \nu \tau$. $\pi v$. und den Körper und die $\mu о \bar{\varrho} \alpha \mathrm{zu}$ einem Teile getrennt, die Seele dagegen und die Kraft zu einem andern Teile getrennt hat, d. h. ,Drei werden gegen zwei und zwei gegen drei gespalten sein'."

Hier wird also die Sündenreinigung ausschließlich den Mysterien der Taufen zugeschrieben, und der Verfasser ist sich ihres Unterschiedes von den Mysterien der drei Erbteile noch klar bewußt. Denn er läßt Maria die weitere Frage stellen (S. 220, 23): „Jetzt dagegen das Mysterium dieser drei Räume und das Mysterium dieses ersten Mysteriums und die Mysterien des Unaussprechlichen, in welchem Typus vergeben sie? Vergeben sie in dem Typus der T'a u fen oder nicht?" Und die Antwort lautet bestimmt: „Nein, sondern alle Mysterien der drei Räume vergeben der Seele 〈in〉 allen Örtern der Archonten alle Sünden, die die Seele von Anfang an begangen hat; sie vergeben sie ihr, und ferner vergeben sie die Sünden, die sie danach begehen wird bis zu der Zeit, bis zu welcher 
jedes Mysterium kräftig sein wird, - die Zeit, bis zu welcher jedes der Mysterien kräftig sein wird, werde ich euch bei der Darlegung des Alls sagen. Und ferner das Mysterium des ersten Mysteriums und die Mysterien des Unaussprechlichen vergeben der Seele in allen Örtern der Archonten alle Sünden und alle Missetaten, die die Seele begangen hat, und 〈nicht nur > sie vergeben ihr sie alle, sondern sie rechnen ihr keine Sünde von dieser Stunde bis in alle Ewigkeit an wegen des Geschenkes jenes großen Mysteriums und seines ungeheuer großen Glanzes."

Wenn nicht alles trügt, so haben wir in den angeführten Mysterien der drei Räume, des ersten Mysteriums und des Unaussprechlichen die höheren Mysterien vor uns, denn das sind ja die großen Mysterien der drei Erbteile, die S. 179, $21 \mathrm{ff}$. den niederen Mysterien in den Büchern des Jeû gegenübergestellt, S. 180, 2 als die Häupter der Mysterien bezeichnet wurden. Während die Mysterien der Taufen in bestimmten Kulthandlungen eine Rolle spielen, in denen durch gewisse Elemente die Körper der Menschen von ihren Sünden befreit werden, daher ihrer Wirkung nach reinigend sind, tragen die anderen Mysterien einen ganz persönlichen Charakter, da hinter ihnen bestimmte Personen der oberen Lichtwelt stehen, vor allem das erste Mysterium und der Unaussprechliche. Ihre Mysterien sind nicht reinigender, sondern vergebender Natur, indem sie die Sünden nicht anrechnen, und zwar diejenigen Sünden, welche nach Empfang der Taufen begangen werden. So erfolgt die Sündenvergebung kraft eines persönlichen Geschenkes aus Erbarmen mit dem reuigen Sünder, "weil barmherzig jene Mysterien sind und vergebend zu jeder Zeit" (S. 222, 21; 223, 27; 225, 30). Diese Mysterien haben nur Wert für den Inhaber selbst, d. h. für den Gnostiker, denn er muB in einem Gebet sich an das betreffende $\mathbf{M y}$ sterium wenden, am Vergebung seiner Sünden zu erhalten (S. 222, 14; 223, 24). Aber zugleich haben diese Mysterien noch eine viel höhere Bedeutung, dab sie nämlich dem Inhaber einen bestimmten Platz im Lichtreich sichern. In unserem Werke nehmen gerade diese Erörterungen über die verschiedenen Rangstufen je nach dem Besitze eines Mysteriums einen groben Raum ein. Das ganze Interesse des Verfassers weilt unbedingt bei diesen höheren Mysterien, die 
er, sollte er sie nicht erst neu eingeführt haben, doch sehr propagandiert. Im früheren Stadium des gnostischen Systems

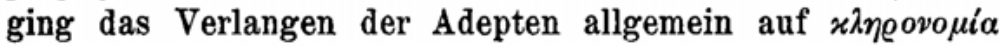
des Lichtreiches aus, d. h. man wollte Mysterien besitzen, mit deren Hilfe die Seele nach dem Tode alle Aeonen der niederen und oberen Welt durchwandern konnte, um zum Lichtschatze zn gelangen. Jetzt hat die ausschweifende Phantasie das Lichtreich in neue Etagen zerlegt, um die Plätzeverteilung unter den Inhabern der verschiedenen neu aufgetauchten Mysterien vornehmen zu können, vor allem wenn bei der

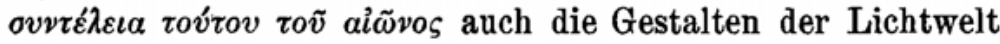
neue Ordnungen einnehmen. Wie man hier von höheren und niederen Örtern in dem Lichte des Reiches Jesu spricht, so auch von höheren und niederen Mysterien. Der Apostel Andreas ist noch ein Vertreter der alten Zeit, wenn jene Darlegungen sein Verständnis übersteigen, und es ist nicht uninteressant $\mathrm{zu}$ sehen, wie Jesus in seiner Antwort den Sprachgebranch der älteren Zeit anwendet. Die Jünger werden nämlich als diejenigen gepriesen, welche gewetteifert und gekämpft haben, indem sie der ganzen Welt und der in ihr befindlichen Materie entsagt and nicht nachgelassen haben zu suchen, bis da $B$ sie alle Mysterien des Lichtreiches fänden, die sie gereinigt und zum reinen Lichte gemacht haben. Und so fährt Jesus in der Rede wörtlich fort (S. 182, 5 ff.): „Deswegen nun habe ich einst zu euch gesagt: ,Suchet, auf dab ihr findet'. Ich habe nun zu euch gesagt: Ihr sollt nach den Mysterien des Lichtes suchen, welche den Körper der Materie reinigen und ihn zu reinem, sehr gereinigtem Lichte machen. Wahrlich ich sage euch: Wegen des Menschengeschlechtes, weil es materiell ist, habe ich mich abgemüht und alle Mysterien des Lichtes ihnen (sc. den Menschen) gebracht, damit ich sie reinige, denn sie sind die Hefe der ganzen Materie, sonst würde keine Seele von dem gesamten Menschengeschlecht gerettet werden, und nicht würden sie das Lichtreich ererben können, wenn ich nicht ihnen die reinigenden Mysterien gebracht hätte. Denn die Emanationen des Lichtes bedürfen der Mysterien nicht, denn sie sind gereinigt, sondern das Menschengeschlecht ist es, das ihrer bedarf, weil 
sie alle materielle Hefen sind". Und deswegen soll die Verkündigung an das ganze Menschengeschlecht lauten (S.182,31 f.): "Nicht lasset nach zu suchen Tag und Nacht, bis daB ihr die reinigenden Mysterien findet" oder S. 183, 14f.: "Nicht lasset nach zu suchen Tag und Nacht, und nicht rastet, bis daB ihr die reinigenden Mysterien findet, die euch reinigen und euch zu reinem Lichte machen werden, so da $\mathrm{ihr}$ nach oben gehen und das Licht meines Reiches ererben werdet."

Die Parallelen zwischen S. $182 \mathrm{f}$. und S. 256f. springen derartig sofort in die Augen, daß ich nicht weiter darauf eingehen will; nur was dort von der Reinigung der Materie im Körper des Menschen gesagt wird, wird hier als Lösung aus den Banden und Siegeln der Aeonen der Archonten bezeichnet; beides ist Bezeichnung eines and desselben Vorganges, nur von verschiedenem Standpunkte aus.

Es steht also fest, daß unter den reinigenden Mysterien die Taufriten $\mathrm{zu}$ verstehen sind, welche für den Eintritt in die gnostische Kultgemeinschaft notwendig sind. Die höheren Mysterien werden den vollkommenen Mitgliedern ohne weiteres zuteil, ohne daß dazu besondere Kultusakte vorgenommen werden.

Wir sind nun auch imstande aus unserem Werke die Zahl dieser Taufen festzustellen. Es wird immer von den Taufen im Plural gesprochen, demnach gab es mebrere ihrer Art. Ihre Zahl belief sich auf drei. Dies erfahren wir aus der Perikope c. 122, nach der eine Frau dreimal getauft war, und auch beim dritten Male hatte sie nicht das den Mysterien des Lichtes Würdige getan. Der Herr will den Petrus versuchen, ob er barmherzig und vergebend wäre. Petrus besteht die Probe und bittet, der Frau die höheren Mysterien zu geben, damit sie, wenn tauglich, das Lichtreich ererbt. Diese drei Taufen müßten wir in den Büchern des Jeû wiederfinden, sollte Jesus m. E. unter den niederen Mysterien die Mysterien der Taufen begriffen haben.

Doch bevor ich zu den Schriften des Codex Brucianus übergehe, wollen wir das Buch IV der P. S. näher betrachten. Jesus verspricht den Jüngern die Schlüssel des Himmelreiches ${ }^{1}$ zu geben und nach einer geheimnisvollen Zeremonie erblicken sie Feuer, Wasser, Wein und Blut. Diese reiches".

1 Vgl. dazu S. 256, 2. 7; 260, 27 „Schlüssel der Mysterien des Licht- 
vier Elemente will Jesus bei seiner Herabkunft in die Welt gebracht haben, und zwar die drei ersten Elemente zur Reinigung aller Sünden der Welt. Analog S. 219, 15 wird hier S. 273, 13 auf Luk. 12, 49 hingewiesen. Die Jünger bitten um Vergebung ihrer Sünden und Missetaten, um dem Reiche seines Vaters würdig zu werden. Er will ihnen das Mysterium des Himmeireiches geben, damit sie selbst sie an den Menschen vollziehen können, und zwar an solchen, in denen kein Falsch ist und die in allen guten Worten auf sie hören (S. 275, 37 f.). Es folgt die eingehende Beschreibung des Ritus (S. 274, $13 \mathrm{ff}$.), der S. 276, $7 \mathrm{f}$. bezeichnet wird als "das wahre Mysterium der Taufe für die, deren Sünden vergeben und deren Missetaten bedecket werden", und weiter als "die Taufe des ersten Opfers, die den Weg zu dem wahren Orte und dem Orte des Lichtes weist." Wenn hier von der

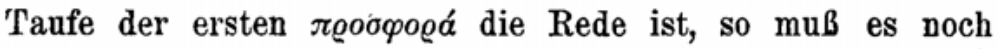

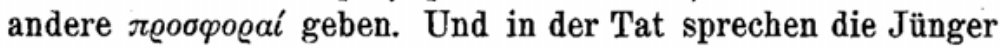
S. 276, 14 ff.: „Rabbi, offenbare uns das Mysterium des Lichtes Deines Vaters, da wir Dich sagen hörten: Es gibt noch eine Feuertaufe, und es gibt noch eine Taufe des heiligen Geistes des Lichtes, und es gibt eine geistige Salbung, welche die Seelen zu dem Lichtschatz führen. Sage uns nun ihr Mysterium, auf dab wir selbst das Reich Deines Vaters ererben". Da haben wir die voraus erschlossenen drei Taufen

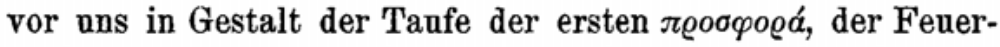
taufe und Taufe des heiligen Geistes. ${ }^{1}$ Die geistliche Salbung ist, wie schon der Name besagt, ein Akt der Salbung nach Empfang der Taufe, darum wird der Ritus auch nicht näher beschrieben. Jesus erklärt nun: „Es gibt kein Mysterium, das vorzüglicher ist als diese Mysterien, nach welchen ihr fragt, indem es eure Seele zu dem Licht der Lichter, zu den Örtern der Wahrheit und der Güte, zum Orte des Heiligen aller Heiligen führen wird, zu dem Orte, in dem es weder Fran noch Mann gibt, noch gibt es Gestalten an jenem Orte, sondern ein beständiges, unbeschreibbares Licht." In dem Buche IV sowohl wie im Buch I-III suchen wir vergeblich nach einer Erwähnung jener drei Tanfen. Daraus ist zu

1 Wegen dieser Taufe erwähnt Jesus S. 273, 4 den heiligen Geist in Gestalt einer Taube. 
schließen, daß der Verfasser eine andere Schrift kannte, in der diese drei Taufen ausführlich behandelt waren.

Nach dieser langen Digression wollen wir uns zu dem zweiten Buche des im Cod. Brucianus enthaltenen ersten Werkes wenden. ${ }^{1}$ Dort finden wir $z u$ unserer Überraschung die gesuchten Mysterien, wenn es heißt: „Aber vor alledem will ich euch die drei Taufen geben: die Wassertaufe und die Feuertaufe und die Taufe des heiligen Geistes. Und ich werde euch das Mysterium geben, die Bosheit der Archonten in euch $z u$ beseitigen, und darnach werde ich euch das Mysterium der geistigen Salbung geben" (S. 305, $17 \mathrm{f}$.). Nun wird S. 308, $14 \mathrm{ff}$. das Rituale der drei Taufen mit dem ganzen Detail der Gebete und der notwendigen Requisiten vorgetragen, dazu kommt S. 313, $1 \mathrm{ff}$. das Mysterium der Beseitigung der Bosheit der Archonten. ${ }^{2}$ Jetzt erkennen wir durch diesen Vergleich mit dem in Buch IV aufgeführten Rituale, da $B$ es sich dort um die Wassertaufe gehandelt hat.

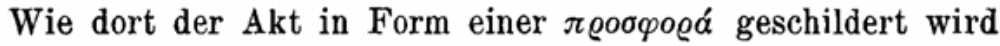
(S. 274, 15. 23; 275, 24. 28), so auch hier neben છvoía (Jeû II

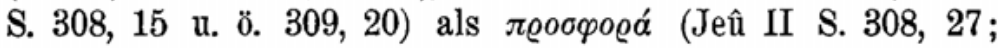
309, 22). Und wenn auch im Einzelnen Abweichungen vorhanden sind, wie die Gegenüberstellung der beiden Stücke in TU VIII S. $497 \mathrm{ff}$. mit voller Deutlichkeit zeigt, so kann um so weniger an der Identität gezweifelt werden, als die Gebete an beiden Stellen an den Vater aller Vaterschaft, das unendliche Licht gerichtet sind (vgl. Buch IV S. 274, 27. 36; 275, 6 mit Jê̂ II, S. 309, 1) und diese Gebete mit den eigentümlichen barbarischen Namen gespickt sind, wie wir sie in den Büchern I-III der Pistis Sophia nicht finden. ${ }^{3}$ Auch erfahren wir aus Jê̂ II S. 309, 3 f. die Namen der Sündenvergeber und Reiniger der Missetaten (vgl. Buch IV S. 274, 38;

1 Koptisch-gnostische Schriften Bd. I S. $303 \mathrm{ff}$.

2 Dieses Mysterium entspricht bei der christlichen Taufe dem Akte der abrenuntiatio von der pompa diaboli.

3 Man darf daraus nicht schließen, daß damals solche Sprache unbekannt war, denn wir finden diese auf dem Lichtkleide Jesu S. 11, 36. Hier erfahren wir, daß es die Schriftart derer von der Höhe ist, d. h. die Sprache der Himmlischen. Daher verkehrt der Beter mit der Gottheit in dieser Sprache. Das ist die Brücke, welche den Gnostizismus mit den griechisch-ägyptischen Zauberpapyri verbindet. 
$275,7 \mathrm{f}$.), als welche die fünfzehn Helfer und die sieben Lichtjungfrauen gelten. ${ }^{1}$ Der Zweck des Sakraments soll sein die Vergebung der Sünden und Austilgung aller Missetaten, die die Seele wissentlich und unwissentlich bis zum Tage des Empfanges des Mysteriums in Hurerei und Ehebruch begangen, um würdig $\mathrm{zu}$ dem Reich des Vaters gerechnet $\mathrm{zu}$ werden (vgl. Buch IV S. 275, 18 f. mit Jeû II S. 309, 10 f.). ${ }^{2}$ Und wenn am Schlub ein Wunderzeichen in dem Opfer als Erkennungszeichen der Erhörung des Gebetes erbeten wird (Buch IV S. 275, 28), so erfahren wir aus S. 309, 20, daß eine Verwandlung von Wein zu Wasser stattgefunden hat. Ohne Zweifel hat der Verfasser des Buches IV ans der Abhandlung des Cod. Brucianus seine Kenntnis des Rituals geschöpft, dabei aber dieses frei behandelt, vor allem in gewissem Sinne gekürzt. Die beiden anderen Taufen dienen dem gleichen Zweck und haben auch die gleiche Wirkung wie die Wassertaufe. Deshalb werden sie den Adepten der Sekte nicht anf einmal appliziert sein, sondern, wie die

1 Die 15 Helfer der 7 Lichtjungfrauen sind auch P. S. S. 144, 4 bekannt. Überhaupt steht die Lichtjungfran sowohl wie die 7 Lichtjungfrauen zu den Taufen in engster Beziehung; sie sind gewissermaßen die Vorsteherinnen und werden in den Taufgebeten besonders angerufen (vgl. Jeû II, S. 310, 41 ff.). Von hier aus verstehen wir erst die Tanfen, welche diese an den Seelen ausüben (P. S. S. 212, 28; 239, 2. 38; 243, 36). Sie müssen mit den irdischen Taufen identisch sein, denn es taucht bei diesem

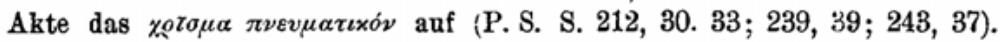
Andererseits prüfen sie auch die Seelen, ob sie jene Taufen mit ihren Siegeln und Zeichen bereits früher empfangen haben (S. 212, 28). Somit sind jene Tanfen der Lichtjungfrau nur eine Dublette der drei Taufen, die der Gnostiker bereits auf Erden empfing, um sich als Adept bei der "Richterin“ legitimieren zu können. Wir können also von nevem konstatieren, daß dem Verfasser der Bücher I-III die drei Taufen nicht unbekannt gewesen sind, vielmehr ihre Kenntnis allgemein vorausgesetzt wird, so daß es einer genaueren Erörterung gar nicht mehr bedurfte.

2 Noch näher berühren sich die Worte im Gebet der Feuertanfe (Jê̂ II S. 310, 15f ): „M Mögest Du ihre Sünden vergeben und ihre Missetaten reinigen lassen, die sie wissentlich und unwissentlich begangen haben, die sie von 〈ihrer〉 Kindheit bis zum heutigen Tage begangen, und ihre Verleumdungen, ihre Flüche, ibre falschen Eide, ihre Unzucht, ihre Ehebrüche, ihre Begierden, ihre Habgier und das, was sie seit ibrer Kindheit bis zum heutigen Tage begangen haben." 
Petrus-Perikope zeigt, je nach dem Rückfall in Sünden. Die Dreiheit führt sich zurück auf das Kerygma Johannes' des Täufers Matth. 3, 11. 12 oder Luk. 3, 16. 17.

Aber diese drei Taufen bilden noch nicht den AbschluB der Mystagogie. Der Verfasser von Buch IV kennt noch ein Mysterium der Sündenvergebung (S. 274, 7), ferner ein Mysterium der sieben Stimmen und ihrer 49 Kräfte (S. 276, 32), und als höchstes das Mysterium des Namens, der vorzüglicher ist als alle Namen, der Name, in dem alle Namen und alle Lichter und alle Kräfte sich befinden, dessen Kenntnis den freien Durchgang durch alle unteren Sphären in das Lichtreich hinein eröffnet (S. 276, $34 \mathrm{ff}$.). Und ferner heißt es S. 265 , 25 ff.: „Ich werde euch das Mysterium der zwölf A e onen der Archonten und ihre Siegel und ihre Zahlen und die Art ihrer Anrufung, um zu ihren Örtern zu gelangen, geben. Und ich werde euch ferner das Mysterium des dreizehnten Aeons geben und die Art der Anrufung, um zu ihren Örtern zu gelangen, und ich werde. euch ihre Zahlen und ihre Siegel geben. Und werde euch das Mysterium der Taufe derer von der Mitte geben und die Art ihrer Anrufung, um zu ihren Örtern zu gelangen, und ihre Zahlen und ihre Siegel werde ich euch verkündigen. Und ich werde euch die Taufe derer von der Rechten, unseres Ortes, geben und seine Zahlen und seine Siegel und die Art der Anrufung, um dorthin zu gelangen. Und ich werde euch das groBe Mysterium des Lichtschatzes geben und die Art der Anrufung, um dorthin zu gelangen. Ich werde euch alle Mysterien und alle Erkenntnisse geben, damit ihr •Kinder der Fülle, vollendet in allen Erkenntnissen und allen Mysterienc, genannt werdet."

Wir werden uns nun nicht weiter wundern, wenn wir in vollständiger Parallele dazu Jeû II S. 305, 7 ff. Folgendes lesen: „Wahrlich, wahrlich, ich sage euch: Ich werde euch das Mysterium der zwölf göttlichen Aeonen geben

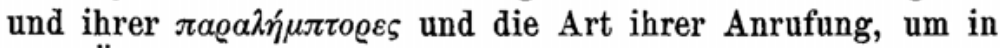
ihre Örter zu gelangen. Und ich werde euch geben das Mysterium des unsichtbaren Gottes ${ }^{1}$ und der $\pi \alpha \varrho \alpha$.

1 Das ist das Mysterium des 13. Aeon, da der unsichtbare Gott daselbst weilt. 


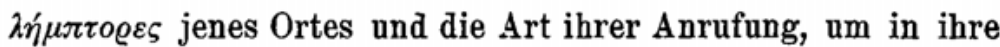
Örter zu gelangen. Und darnach werde ich euch lehren das Mysterium derer von der Mitte und der $\pi \alpha \varrho \alpha \lambda \tilde{\eta} \mu \pi \tau \alpha \iota$ und die Art ihrer Anrufung, um in ihre Örter zu gelangen. Und ich werde euch geben das Mysterium derer von der Rechten und ihrer $\pi \alpha \varrho \alpha \lambda \tilde{\eta} \mu \pi \tau a \iota$ und die Art ihrer Anrufung, um in ihre Örter zu gelangen." Wiederum kann nicht zweifelhaft sein, wo das Original und wo die Kopie, denn in unserer Abhandlung werden diese Mysterien ausführlich geschildert (S. 322, 2 ff.), wenn auch der Schluß uns nicht mehr erhalten ist. In Buch IV hat der Verfasser sich nur mit der Ankündigung begnügt, denn in der Lücke von 8 Seiten kann unmöglich ihre Darstellung stattgefunden haben. Diese soeben anfgeführten Mysterien dienen nicht wie die Mysterien der Taufen der Sündenvergebung, sondern ermöglichen der Seele durch die Kenntnis der Siegel, Zahlen, Namen, Apologien und Anrufungen die Reise durch die niedere und obere Aeonenwelt.

Für die Reise durch die höhere Lichtwelt bis zum Lichtschatze ist dagegen der Besitz des Mysteriums der Sündenvergebung notwendig. „Dieses ist das große Mysterium, das sich in den Schätzen des Innern der Innern befindet, und es ist das gesamte Heil der Seele. ... Deshalb nun muß jeder Mensch, der an den Sohn des Lichtes glaubt, das Mysterium der Sündenvergebung empfangen, damit er ganz vollkommen und in allen Mysterien vollendet sei, denn es ist das Mysterium der Sündenvergebung. ... Deswegen nun sage ich ench: Wenn ihr das Mysterium der Sündenvergebung empfangt, so werden alle Sünden, die ihr bewußt und unbewußt begangen, die ihr seit eurer Kindheit bis zam heutigen Tage und bis zur Auflösung des Bandes des Fleisches der Heimarmene begangen habt, sämtlich ausgetilgt werden, weil ihr das Mysterium der Sündenvergebung empfangen habt" (Jeû II S.314, $27 \mathrm{ff}$.). Dann fliehen alle Aeonen, sobald die Seele nach ihrem Ausgang aus dem Körper dieses Mysterium mit seinen Apologien, Siegeln, Zahlen und Deutungen hersagt; die Wege der Aeonen werden gereinigt, und somit gelangt die Seele ungehindert zu den Toren des Lichtschatzes und werden ihr die Tore von den Wächtern geöffnet. Die Reise einer mit dem Mysterium der Sündenvergebung ausgerüsteten Seele durch 
die Lichtaeonen von den drei Amen bis zum Schatze des wahren Gottes wird Jeû II von S. 315, 37-321, 5 beschrieben. Freilich die angekündigte Beschreibung des Mysteriums der Sündenvergebung (vgl. auch S. 321, 12 f.) ist infolge des Verlustes des Schlusses nicht mehr auf uns gekommen.

Auch dem Verfasser von Buch IV ist das Mysterium der Sündenvergebung nicht unbekannt, da er es S. 274, 7 erwähnt; er vindiziert diesem Mysterium die Binde- und Lösegewalt im Himmel und auf Erden. Dagegen ist in dem Kataloge der Mysterien das Mysterium der Sündenvergebung unter dem großen Mysterium des Lichtschatzes begriffen (S. 266, 4), das ja auch oben an der angeführten Stelle in Jeû II „das große Mysterium, das sich in den Schätzen des Innern der Innern befindet" genannt wird. Und wenn es Jeû II S. 307, $39 \mathrm{f}$. heißt: „Und ich werde euch alle Mysterien geben, damit ich euch in allen Mysterien des Lichtreiches vollende, und ihr sKinder der Fülle, vollendet in allen Mysterien', genannt werdet", so hat der Verfasser von Buch IV seine Vorlage einfach etwas abgewandelt, um nicht direkt ein Plagiat zu begehen, da wir S. 266,6f. lesen: „Ich werde euch alle Mysterien und alle Erkenntnisse geben, damit ihr 'Kinder der Fülle, vollendet in allen Erkenntnissen und allen Mysterien c genannt werdet. Selig seid ihr vor allen Menschen, die auf Erden, denn die Kinder des Lichtes ${ }^{1}$ sind zu eurer Zeit gekommen."

Nun hatte Jesus in Buch IV S. 276, 32 f. von Mysterien gesprochen, die vorzüglicher sind als die Taufmysterien, und als solche das Mysterium der sieben Stimmen und ihrer 49 Kräfte und das Mysterium des (großen) Namens ${ }^{2}$ genannt. In Jeû II waren die Jünger, als Jesus ihnen die Mysterien der Taufen in Aussicht gestellt' hatte, schreiend und weinend ihm zu Füßen gefallen mit den Worten: „O Herr, weshalb hast $\mathrm{Du}$ nicht $\mathrm{zu}$ uns gesagt: Ich werde euch die Mysterien des Lichtschatzes geben" (S. 306, 1). Als Mysterien des Lichtschatzes führt Jesus die Mysterien der 9 Wächter, des

1 Den Ausdrack ,Kinder des Lichtes" finden wir auch Jeâ II S. 304, 38. $39 ; 321,14.20$.

2 Der "große Name" ist der Name des Vaters des Lichtschatzes S. $262,9.12 ; 272,18.24 ; 274,25$. 
Kindes des Kindes, der drei Amen, der fünf Bäume, der sieben Stimmen und der 49 Kräfte und des großen Namens 'aller Namen, d. h. des großen Lichtes, das den Lichtschatz umgibt, auf. Wiederum ertappen wir den Verfasser von Buch IV dabei, wie er aus diesem Katalog die beiden letzten, d. h. höchsten Mysterien aufgenommen hat.

Aber auch in Kleinigkeiten anderer Art hat dieser Kompilator seinen Vorgänger ungeniert ausgeplündert. 1. $\mathrm{Zu}$ Anfang von Buch IV bitten die Jünger den Herrn sich ihrer zu erbarmen, da sie Vater und Matter und die ganze Welt verlassen und ihm gefolgt sind (S. 261, 4 f., vgl. S. 265, 23 f.). In Jeû II S. 305, $3 \mathrm{ff}$. lesen wir: „Jetzt nun, da ihr eure Väter und eure Mütter und eure Brüder und die ganze Welt verlassen habt und mir gefolgt seid und alle Befehle, die ich euch aufgetragen, vollführt, jetzt nun hört mich" und S. 306, 3 ff.: „Das Herz Jesu war aber betrübt über seine Jünger, weil sie ihre Eltern und ihre Brüder und ihre Franen und ihre Kinder und alle Güter dieser Welt verlassen hatten und ihm zwölf Jahre ${ }^{1}$ gefolgt waren und alle Gebote, die er ihnen befohlen, befolgt hatten".

1 Nicht geklärt ist, was unter diesen 12 Jahren zu verstehen ist, ob es sich um das gesamte Erdenleben Jesu handelt oder um den 12 jährigen Verkehr des Auferstandenen mit den Jüngern. In dem Eingange S. 303, 1 f. wird ohne jede Zeitangabe von einer Versammlung der Jünger und Jüngerinnen gesprochen. Ebensowenig kann man mit Sicherheit feststellen, ob das erste Buch auf Gespräche Jesu nach der Auferstehung zurïckgeführt wird. Jesus wird hier der Lebendige genannt, der aus dem Lichtaeon in der Fülle des Pleroma herausgekommen ist und nun als Lehrer auftritt, der die Lehre bringt, in der die gesamte Erkenntnis wohnt. Von seiner Kreuzigung ist nirgends die Rede, oder man müBte in den Worten der Einleitung: ${ }_{n}$ Selig ist der, welcher die Welt gekreuzigt hat und nicht die Welt hat ihn kreuzigen lassen" eine Anspielung daran erblicken. Auch weisen die Jünger darauf hin, daß sie Jesu gefolgt sind mit ganzem Herzen and Vater und Mutter verlassen haben (S. 258, 5), aber eine nähere Zeitangabe vermissen wir auch hier. So scheint die Zeit der Unterredung in der Schwebe gehalten zu sein. Ich habe den Eindruek, als habe der Verfasser der Bücher I-III die Stelle in Jeû II falsch aufgefaßt und daraus 12 Jahre nach der Auferstehung erdichtet. Wenn der Verfasser von Buch IV die Unterredungen unmittelbar in die Zeit nach der Auferstehung verlegt, so kann ich aus diesem Dissensus keine Schlußfolgerungen für die Datierung der Bücher sehen, wie es Liechtenhan tut, denn in dieser Beziehung hatte der Kompilator freie Hand, aber auch jeder andere Verfasser. 
2. Die Übergabe der Mysterien darf nur an gläubige Menschen erteilt werden, sonst ist Geheimlehre geboten, daher "verberget dieses Mysterium und gebet es nicht allen Menschen, außer demjenigen, der alle Dinge tun wird, die ich euch in meinen Geboten gesagt habe" (Buch IV, S. 276, 3 f.). Und in gleicher Weise heißt es in Jeû II : „Diese Mysterien, die ich euch geben werde, bewahret und gebet sie keinem Menschen, sie seien denn ihrer würdig" etc. (S. 304, 6 f. 32 f.; 305, 1 f.). Würdig ist aber derjenige, der Jesu Gebote vollführt hat (S. 305, 5. $34 ; 306,6)$.

3. In Jeû II S. 304, $17 \mathrm{f}$. las der Verfasser von Buch IV von einer scheußlichen gnostischen Sekte, deren Mitglieder das Menstrualblut der Weiber und den Samen der Männer beim Abendmahl verzehren und frech behaupten, sie wären im Besitze der wahren Erkenntnis und beteten zum wahren Gotte. Diese Kunde hat er S. 282, $33 \mathrm{f}$. verwertet.

4. In Jeû II S. 308, 6 f. befiehlt Jesus, bevor er das Mysterium der Taufen vollzieht, den Jüngern, nach Galiläa hinaufzugehen und zwei Krüge Weins aus den Händen einer Person, sei es Mann oder Frau, die keinen Geschlechtsverkehr mehr ausüben, zu nehmen. Darnach würde Judäa als Schauplatz der Unterredungen gelten, da man von hier aus nur von einem „hinaufgehen" reden kann; freilich müßten dann in zauberhafter Schnelligkeit alle Jünger den Befehl ausgeführt haben. Nach Buch IV S. 273, 33 ist der Schauplatz der Mysterienmitteilung der Berg von Galiläa.

5. In Jeû II S. 320, 10 kommt im Gebet $\varepsilon \iota a \pi \tau \vartheta \alpha \varepsilon \iota \alpha \pi \tau \vartheta \alpha$ vor und folgt die Erklärung: "Vater aller Vaterschaft, denn das All ist aus dem Alpha herausgekommen und wird zu dem Omega zurückkehren, wenn die Vollendung aller Vollendung statthaben wird." Ein ähnliches Gebet an den Vater aller Vaterschaft beginnt in Buch IV S. 262, 3 mit dem Anruf $\ddot{a} a \varphi \vartheta a^{*} \ddot{i} a \varphi \vartheta \alpha$; vorhergeht die Deutung des Namens ¿a $\omega$ : „Jota, das All ist herausgegangen - Alpha, es wird sich wieder zurückwenden - Omega, es wird die Vollendung aller Vollendungen stattfinden!"

6. In Jeû II werden alle Gebete bei den Taufen gegen die 4 Ecken der Welt gesprochen (S. 308, 34; 310, 11; 312, 37; 
313, 33). Die gleiche Gebetsstellung kennt auch Buch IV S. 261,$22 ; 272,24$.

Man könnte noch eine Reihe Parallelen im Sprachgebrauch anführen, aber das Vorgetragene wird zum Beweise vollauf genügen, daß der Verfasser von Buch IV das Buch Jeû II für den Teil seiner Schrift, der sich mit dem Mysterienwesen der gnostischen Sekte beschäftigt, als Vorlage benutzt hat. ${ }^{1}$ Von parallelen Redaktionen, wie Liechtenhan annimmt (l. c. S. 244), kann m. E. nicht die Rede sein. Die Abhandlung, welche er vor sich hatte, umfaßte die gesamte Mystagogie, wie sie in älterer Zeit ausgebildet war und auch noch in späterer Zeit die Grundlage bildete. Mit Recht sagt Liechtenhan, daß Sekten sich in erster Linie um denselben Kultus, erst in zweiter Linie um dieselbe Lehre scharen. Irgendwelche Mysterien außer den in der Grundschrift vorgeführten finden wir nirgends.

Hat aber Jeû II die Grundschrift für die gesamte Mysterienlehre gebildet, so muß auch der Verfasser von Buch I-III die Schrift gekannt haben, wenn er zu den Häuptern derselben gnostischen Sekte gehörte. Sehen wir zunächst von der Mysterienlehre ab, so ist die Übereinstimmung in der Kosmogonie eine höchst frappante. Im Lichtschatz z. B. treffen wir nicht nur auf dieselben Namen, sondern auch auf dieselbe Reihenfolge; die $9 \mathrm{Wächter}$ die 3 Amen, das Kind des Kindes, Soterzwillinge, die

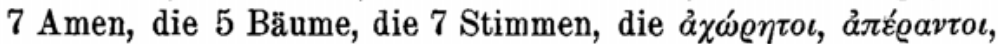
ả $\sigma a ́ \lambda \varepsilon v \tau o \iota$ etc., aber die mit $\pi \varrho o-$ und $v \pi \varepsilon \varrho-$ gebildeten Namen wie

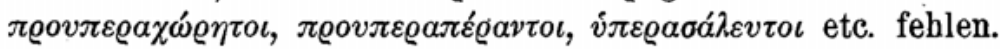
Diese Personen sind sicherlich dem Verfasser nicht unbekannt gewesen, aber er hat das Personal in etwas reduziert, da er auf der anderen Seite auch neue hinzugefügt hat. Nan, in dieser Beziehung haben ja die einzelnen Häupter sich große Freiheiten erlaubt, and man darf auf derartige Differenzen kein zu großes Gewicht legen. Aber nicht irrelevant sind die Differenzen in bezug auf die Spitze des

1 Auch in dem Teile, der sich mit den furchtbaren Strafen der Archonten des Weges der Mitte beschäftigt, scheint fremdes Material benutzt za sein. So z. B. kommen die Namen dieser Archonten ebenfalls in einem Fragment des Cod. Bruc. vor (S. 333, $35 \mathrm{ff}$.), und zwar werden genannt Paraplêx, Typhon und Jachthanabas. 
ganzen Universums. Denn nach Jeû I und II ist das höchste Wesen der „unnahbare Gott", das „alleinige Sein“, von dem der Lichtschatz emaniert ist; in diesem herrscht der "wahre Gott". Daneben existiert noch ein zweiter Lichtschatz, in welchem Jeû, das „große Licht", „der Vater des Lichtschatzes“, der „große Mensch“, der „König des Lichtschatzes" herrscht, von dem wieder 60 Lichtschätze emaniert sind, die alle den Namen des Jeû tragen. In Buch I-III der P. S. steht der Unaussprechliche resp. Unbeschreibliche an der Spitze des Universums; ${ }^{1}$ aus ihm ist von Anfang an das erste Mysterium hervorgegangen, das der gesamte Ausgang aller Emanationen und aller Mysterien ist, deshalb der „Herr des Alls". Dementsprechend auch die höheren Mysterien. Das höchste Mysterium ist das einzige Mysterium des Unaussprechlichen, das wieder in drei Mysterien zerfällt. Daneben gibt es noch fünf Mysterien des Unaussprechlichen. Das erste Mysterium umfaßt 12 Mysterien und daran schließen sich die

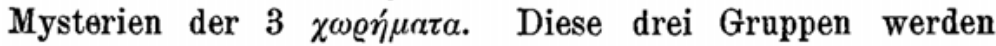
zusammengefaßt, wie bereits erwähnt, unter dem Namen der drei Erbteile. Hier herrscht nämlich die Vorstellung, daß die Inhaber dieser Mysterien je nach dem Grade einen höheren oder niederen Platz in den Erbteilen des Lichtes erhalten (S. 178, 5 ff.), demgemäß der Inhaber des höchsten Mysteriums, d. h. des Mysteriums des Einzigen, Unaussprechlichen, sich mit den Gliedern des Unaussprechlichen vereinigen wird (S. 166, 29). Die Darlegung dieser Mysterien und zugleich ihre Wirkungen in der Sündenvergebung nehmen einen breiten Raum in den beiden letzten Büchern des Werkes ein. Diese ganze Gruppe von Mysterien ist dem großen Mysterienbuche ganz fremd, infolgedessen ist sie auch dem Verfasser von Buch IV unbekannt geblieben. Deswegen aber waren die alten Mysterien noch nicht vollständig abrogiert; vor allem die Mysterien der Taufen, welche nach wie vor die Sühneriten für die gewonnenen Mitglieder bildeten, konnten in der Mystagogie der späteren Zeit auf keine Weise ersetzt werden. ${ }^{2}$ Deshalb tauchen sie

1 Nur an einer einzigen Stelle, nämlich S. 176, 33, ist die Rede von den "Gliedern des Unaussprechlichen, die zu der Oikonomie des Einzigen, des wahren, unnahbaren Gottes gehören ${ }^{\prime}$. Das erinnert noch dunkel an eine frühere Phase des Systems.

2 Die Behauptung von Liechtenh., die Sekte, welche Buch II-III 
auch, wie ich vorhin ausgeführt habe, wieder auf, aber eine Sonderbeschreibung glaubte der Verfasser sich schenken zu können, da er auf eine schriftliche Darstellung verweisen konnte. Er bezeichnet diese Quelle mit dem Titel: „die beiden (großen) Bücher des Jeû" oder einfach „die Bücher des Jeû".

Damit stehen wir vor der Entscheidung, ob das im Cod. Bruc. enthaltene Werk tatsächlich mit den beiden Büchern des Jeû zu identifizieren ist. Folgende Anforderungen sind zu erfüllen: 1. das Werk muß zwei Bücher umfassen, 2. es muß den Titel „Jêै" rechtfertigen, 3. es muß die reinigenden Mysterien, speziell die Taufriten enthalten. Der erste Punkt ist schnell erledigt, da ja unser Werk ebenfalls zwei Abhandlungen enthält. Das ist schon ein gates Präjudiz für die Identität. Man könnte vielleicht daran AnstoB nehmen, da $B$ die Mysterien nur in dem zweiten Buche enthalten sind. Aber wir haben kein Recht, das Zitat so auszulegen, als hätte die Darstellung der Mysterien alle zwei Bücher angefüllt. An der zweiten entscheidenden Stelle S. 258 wird ja nur allgemein von den Büchern des Jeû gesprochen. - Auch der dritte Punkt macht keine Schwierigkeiten. Wir dürfen uns nicht verwirren lassen durch die Unterscheidung von niederen und höheren Mysterien, denn diese war an der ersten Stelle S. 179 nur durch den Zusammenhang veranlaßt, wo von höheren und niederen Plätzen je nach dem Range der Mysterien die Rede war. An der zweiten Stelle handelt es sich ganz allgemein um Mysterien, die für die Sünder sowohl wie für die Gerechten heilsnotwendig sind. Der Begriff "niedere" und "höhere" Mysterien spielt dabei absolut keine Rolle. In den einleitenden Worten zu dem Mysterienbuche spricht Jesus von den großen Mysterien des Lichtschatzes, die er verkünden will, die niemand an dem unsichtbaren Gotte kennt, auf Grund deren Kenntnis die Seelen in den Lichtschatz geführt werden, nachdem alle Sünden, die sie wissentlich und die sie unwissentlich begangen, ausgelöscht sind (Jeû II S. 303, 6 ff.). Bei diesen großen Mysterien des Lichtschatzes handelt es sich um die Präparierung der gnostischen brauchte, hätte gewiß die Bücher Jeû aus dem Gebrauch ausgeschaltet, wenn niedere Weihen darin als die höchsten wären bezeichnet worden, richtet sich von selbst. 
Seele für ihre letzte Reise durch die gesamte Aeonen- und obere Lichtwelt bis zum höchsten Ort; deshalb heißt es auch S. 303, $20 \mathrm{f}$ : "Und die Seele springt beständig von Ort zu Ort, bis sie zu dem Lichtschatze gelangt. Und sie wandern hinein in das Innere der Wächter des Lichtschatzes; und sie wandern hinein in das Innere der drei Amen, und sie wandern hinein in das Innere der Zwillinge . . . und sie befinden sich in dem Orte, der innerhalb von ihnen ist, d. h. in dem Orte der Unfaßbaren des Lichtschatzes." Denn die Gnosis übte ja gerade durch ihre Propaganda einen so großen Eindruck auf die Volksmasse aus, als sie ihren Adepten gegenüber sich als Versicherungsanstalt für die Himmelsreise der Seelen anbot. ${ }^{1}$ Dazu hatte aber jeder Einzelne die Kenntnis der Siegel, Zahlen, Namen, Apologien etc. der einzelnen Aeonen nötig. Deshalb werden diese Requisite der Mystagogie in unserer Abhandlung ganz ausführlich den Lesern unterbreitet, während in Buch II-III der P. S. ganz allgemein von diesen Dingen gesprochen wird. ${ }^{2}$ Deswegen waren aber diese Mysterien nicht obsolet geworden, nur brauchte der Verfasser kein Interesse für diese Seite der Mysterienlehre zu zeigen, weil diese in früherer Zeit bereits festgelegt war.

Damit wende ich mich zu dem zweiten Punkte. Hier setzt vor allem die Kritik ein. Denn Liechtenhan macht im Anschluß an Preuschen geltend, daß die Bücher Jê̂ ein Diktat des präexistenten Jesus an Henoch enthalten hätten, das erste Buch des Cod. Bruc. erzähle aber Offenbarungen des auferstandenen Jesus an seine Jünger, ja eine Reise Jesu und der Jünger durch die Himmel. So ergebe sich, daß Jesus dem Henoch die Erzählung eines Vorganges diktiert habe, der erst viel später stattfand. Henoch sei daselbst mit keinem Worte erwähnt; daß Jesus den Jüngern den Inhalt eines Buches mitteile, sei mit keiner Silbe angedeutet. Wenn Jesus ausführlich die komplizierten Veranstaltungen zur Be-

1 Vgl. die Ausführungen von Anz, Zur Frage nach dem Ursprang des Gnostizismus, S. $9 \mathrm{ff}$., besonders S. $26 \mathrm{f}$.

2 In Buch II-III werden vielfach die Siegel, Zahlen, Apologien, Namen, Zeichen der einzelnen Mysterien erwähnt, aber ihr Aussehen wird nicht näher angegeben, nur S. 174, 36 heißt es von „einem Siegel, welehes dieses ist ${ }^{\mu}$. Hier müßte die betreffende Form des Siegels angegeben sein, von denen Jeû I und II ganz angefüllt sind. 
wahrung der Bücher Jeû während der Sintflut erzähle, könne das nur den Sinn haben, daß Henochs eigenhändiges Manuskript vor den Fluten gerettet worden sei und den Jüngern ausgehändigt werden solle; davon finde sich in dem Werke keine Spur. Wenn es nur heißen solle, der Inhalt der Bücher Jeû sei schon dem Henoch bekannt gewesen, wozu dann die Rettung während der Flut? - Selbst wenn ich die Autorschaft des Henoch heute akzeptierte, würde dies meine These noch keineswegs erschüttern. Denn zwischen der Einleitung und den Ausführungen über die Kosmogonie ist ja eine große Lücke. Konnte nicht im Verlaufe der Unterredung Jesus seine Jünger auf die Tatsache hinweisen; er habe bereits in der Urzeit der Menschheit die gnostische Weisheit dem Henoch in die Feder diktiert und dafür Sorge getragen, da $B$ dieses Diktat in zwei Büchern vor der Vernichtung durch die Sintflut gerettet wäre! ${ }^{1}$ Denn auf jeden Fall war diese Legende eine Fiktion eines gnostischen Autors, der sein eigenes Geistesprodukt mit dem Nimbus der Uroffenbarung umkleiden wollte. In Wirklichkeit mußte ja Jesus wieder als Offenbarer an die Jünger auftreten, da die Bücher Jeû auch seit der Sintflut der Menschenwelt verborgen geblieben waren, so daß selbst die Patriarchen und Propheten des A. T.s keine Ahnung von diesem Mysterienbuche hatten. So wollte dieser Gnostiker sein Elaborat unter den Schutz der Uroffenbarung stellen. Die Person des Henoch spielt dabei nur eine Nebenrolle, wie z. B. der Apostel Philippus in der P.S. Denn wenn es nicht ausdrücklich gesagt wäre, würde niemand auf den Gedanken kommen, eine Niederschrift der Taten und Reden Jesu aus seiner Hand zu besitzen. - Vor allem aber gibt Liechtenhan keine Antwort auf die Frage, wie ein Werk, das Henochs eigenhändiges Manuskript sein soll, nicht seinen Namen, sondern den des Jeû trägt. Dann muß doch die Person des Jeû in dem Werke eine hervorragende Rolle gespielt haben. Denn „Bücher des Jê̂" kann nichts anderes bedenten als

1 Ich kann aber auch heute noch nicht glauben, $\mathrm{da} B$ diese Legende irgendwo in dem betreffenden Werke gestanden hat. Denn es soll ja auch dort gestanden haben, daß der Archon Kalapatauroth, der über das Siebengestirn, auf dessen Haupt der $\mathrm{FuB}$ des Jê̂ steht, als Wächter fungiert habe. Hier erscheint Jeû bereits wie in Buch I-IV in der niederen Sphäre als der Ordner der Archoutenwelt (s. u. S. LXXX). 


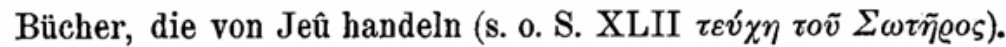
Und nun vertiefe man sich in das erste Buch! Von S. 260, 21 bis S. 295, 8 wird in ermüdender Breite die Gestalt des Jeû und seiner 60 Schätze beschrieben. Die Jünger selbst haben die Örtlichkeiten in Begleitung Jesu schauen können and bitten jetzt um die Mitteilung des großen Namens, ${ }^{1}$ vor dem die Örter aller Schätze sich zurückziehen und den Anrufenden bis zu dem Orte des wahren Gottes gelangen lassen (S. 295, 9 ff.). Das Ganze schlieBt mit einem groben Hymnus auf den Vater, den Unnahbaren selbst. Es folgt die

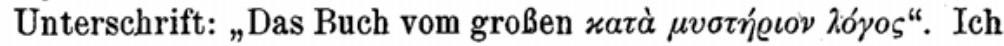
hatte nun in meinen Untersuchungen über den Titel (TU VIII S. 26 f.) den Nachweis zu führen gesucht, daß der vollständige

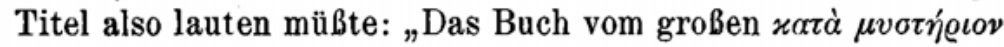

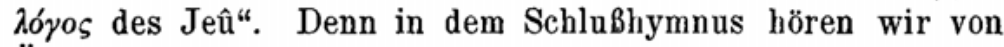

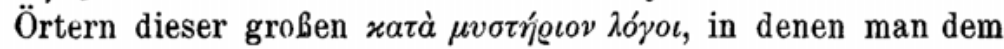
Unnahbaren genaht ist, und in denen er sich selber emaniert hat. Diese hófor sind die Emanationen, welche "Jeû" genannt werden. Neben diesen Jeû's steht der große $x \alpha \tau \dot{\alpha} \mu v \sigma \tau \eta \dot{\varrho} \iota \nu$

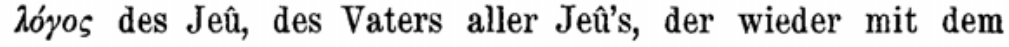
Unnahbaren identifiziert wird. In diesem großen $\varkappa \alpha \tau \grave{\alpha} \mu v \sigma \tau \eta \dot{~-~}$

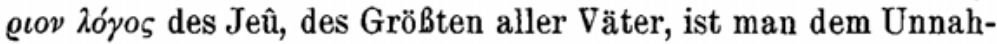
baren nahe gekommen, während der Unnahbare selbst sich in sein Abbild und seine Idee zurückgezogen hat. .So kann

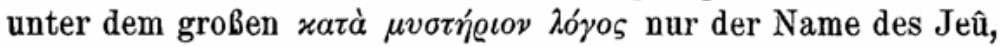
des Größten aller Väter, d. h. der 60 Jeû-Vaterschaften, verstanden werden. Wollen wir "Jeû" im Titel nicht ergänzen, so müssen wir ihn nach dem Inhalt des Werkes mit innerer Notwendigkeit hinzudenken. Und wenn nun der Verfasser der P. S. schlechtweg von den Büchern des Jeû spricht und nicht den ganzen Titel nennt, so liegt die Ursache nicht darin, $\mathrm{da} B$ unser Buch nicht gemeint ist, sondern darin, daß niemand den Titel in der längeren Form überhaupt verstanden bätte, wenn er nicht die Schlußsätze des Hymnus vor sich gehabt; denn ich fürchte, daß auch Liechtenh. mit dem Titel „Buch

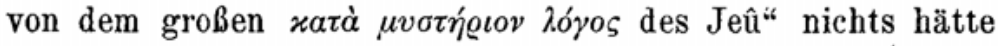
anfangen können, wenn er ihn in dieser Form in der P. S. vorgesetzt erhalten hätte; andererseits konnte in der abgekürzten

1 Das ist derselbe "große Name" wie in Jeû II und Buch IV. 
Form wenigstens so viel verstanden werden, daß die Person des Jeû in diesem Werke speziell behandelt war. Wer würde

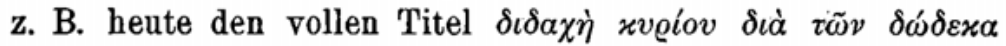
ảлоблó $\lambda \omega \nu$ angeben und nicht einfach von der Didache sprechen! Ebenso wußte jedes eingeweihte Mitglied, was unter den „Büchern des Jê̂" zu verstehen sei; eines weiteren Kommentars bedurfte es nicht. Und war denn die Líteratur dieser Gnostiker so umfangreich, daß ihre Mystagogie in so vielen verschiedenen Schriften umlief?

Und nun zum letzten Einwurf, daß, wenn der Name des Jeû im Titel des ersten Buches angenommen werden mub, dies noch nicht für das zweite Buch zo gelten hat, auf das es in der Hauptsache ankommt. Hier ist ja der Titel verloren; auch glaube ich nicht, daB dieses Buch in seinem Titel den Namen des Jê̂ getragen hat, da seine Figur hier gar keine weitere Bedeutung hat, als daß er der "große Mensch", der „König des ganzen Lichtschatzes“, der "Vater des Lichtschatzes" in Übereinstimmung mit der Stellung in der Kosmologie des ersten Buches genannt wird. Aber da diese beiden Bücher in der Überlieferung miteinander verbunden waren und wahrscheinlich auch aus der Feder eines und desselben Verfassers stammten, bezeichnete man beide im abgekürzten Verfahren mit dem Titel „der Bücher des Jê̂". Solche gemeinsame Zitierung trotz verschiedener Titel ist doch keineswegs so ungewöhnlicher Natur, als daB man deshalb selbst eine nicht ganz sicher fundierte Hypothese über Bord werfen würde! ${ }^{1}$ Von irgendwelchem Zweifel kann aber m. E. angesichts der gewonnenen Resultate nicht mehr die Rede sein. In der Zeit des Verfassers von Buch II-III der P. S., ja des Verfassers von Buch IV hätte wohl kaum jemand ein Buch nach Jeû betitelt. Denn in diesen Werken nimmt Jeû nicht mehr den höchsten Rang nach dem Unnahbaren ein, sondern er befindet sich im Topos der Rechten außerhalb des Lichtschatzes, und zwar als der oberste Herrscher dieser Region neben fünf anderen großen Fürsten. In Buch IV

1 Ich möchte z. B. auf die Tatsache hinweisen, daß der 2. Clemensbrief durch die handschriftliche Verbindung mit dem 1. Clemensbriefe resp. durch den gemeinsamen Gebrauch im Vorlesegottesdienst seinen echten Titel verloren hat und von jetzt ab als 2. Clemensbrief tradiert wurde. 
hat er folgende Funktionen: 1. Fürsorge aller Archonten, Götter und Kräfte, die aus der Materie des Lichtes des Schatzes entstanden sind (S. 266, 38). 2. Er gehört mit Zorokothora Melchisedek zu den beiden großen Lichtern, die von Zeit zu Zeit in die Archontenwelt hinabgehen und das dort gewonnene, gereinigte Licht einsammeln und in den Lichtschatz führen (S. 267, 5 ff.). 3. Jeû hat schon früher die aufsässige Archontenwelt unter Sabaoth Adamas in die Sphära der Heimarmene gebunden und hat im Zusammenhange damit die Planetenwelt geordnet (S. 263, 8 ff.). In gleicher Weise hat er auch die Archontenwelt des Weges der Mitte geschaffen (S. 266, $13 \mathrm{ff}$.). 4. Jeû wird von Jesus der Vater seines Vaters genannt (S. 263, 12. 23; 266, 13. 38).

Noch mehr erfahren wir über Jeû in den Büchern I-III. Hier führt er folgende Ehrentitel: 1. Gesandter des 1. Gebotes (S. 235, 14; 243, 16), 2. der erste Mensch $^{1}$ (S. 208, 36; 235, 13; 243, 14. 16. 17), 3. Aufseher des Lichtes (S. 18, 9; 24, 24. $28 ; 143,3.14 ; 235,13$ ), 4. Engel des Lichtes (S. 67, 8. $11 ; 69,20)$. 5. Nach den Ausführungen auf S. 143, 3 ff. ist Jeû aus dem reinen Lichte des ersten Baumes hervorgegangen, und hat der letzte Helfer auf Befehl des ersten Mysteriums ihn mit den fünf andern Herrschern ${ }^{2}$ an den Ort derer von der Rechten gebracht behufs Verwaltung der Einsammlung des Lichtes aus den Aeonen der Archonten. Wegen dieser wichtigen Funktion wird er mit den andern beim Aufstieg des Alls Mitkönig sein in dem ersten Erlöser der ersten Stimme des Lichtschatzes (vgl. S. 142, 28 f.).

6. Aus Jeû ist Sabaoth, der Große und Gate, hervorgegangen; letzteren nennt Jesus seinen „Vater" (S. 143, 12f.; 212, 36f.), ${ }^{3}$ daraus leitet sich in Buch IV der Name des Jeû als "Vater meines Vaters" ab.

7. Jeû hat auf Befehl des 1. Gebotes and des 1. My-

1 Das erinnert noch an seine frühere höhere Stellung, da er in Jeû II S. 318, 35 der „große Mensch ${ }^{\text {}}$ genannt wird.

2 Ihre Namen sind: Wächter des großen Lichtes, die beiden großen

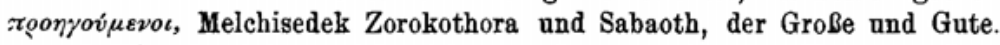

3 Hier handelt es sich nicht um den präexistenten Vater, sondern um den Vater beim Herabstieg, indem Jesus aus Sabaoth eine Lichtkraft genommen und in seinen materiellen Körper gestoßen hat (S. 10, 5; 20, 7; $91,20$. 29. $35 ; 92,19 ; 93,1 ; 94,24 ; 95,10.20)$. 
steriums die Stellung der Archonten der Sphära und Heimarmenè festgesetzt (S. 18, 9; 22, 6; 24, 24. 27).

Einen größeren Gegensatz zwischen der Stellung des Jeû in den beiden Werken des Cod. Bruc. und derjenigen in den Büchern I-IV kann es wohl kaum geben. Da in der P. S. Buch IV und I-III eine frappante Übereinstimmung zeigen, müssen sie eine gemeinsame Vorlage benutzt haben. In einem Fragment eines gnostischen Gebetes, das sich in dem Sammelbande des Cod. Bruc. befindet, besitzen wir ein Gebet an das 1. Mysterium, wo Jeû auf dessen Befehl die 13 Aeonen mit ihren Archonten, Dekanen, Liturgen einsetzt. ${ }^{1}$ Offensichtlich stammt dieses Gebet aus späterer Zeit, da es an das 1. Mysterium gerichtet ist. Wir können daraus entnehmen, daß in einem größeren gnostischen Werke der späteren Zeit die Stellung des Jeû im Universum eine Veränderung erfahren hatte, indem er seine frühere beherrschende Position eingebüßt hatte. Diese Degradierung können wir auch bei andern Personen feststellen, so z. B. bei Jaldabaoth, dem großen Sabaoth, dem großen Jaô.

Damit glaube ich in etwas den Urwald gelichtet and das Dunkel gelüftet zu haben, das über die koptisch-gnostische Literatur noch immer herrscht; vor allem hoffe ich, das gegenseitige Verhältnis der in Frage kommenden Werke genauer aufgehellt and zugleich die Datierungen auf eine sichere Grundlage gestellt $\mathrm{zu}$ haben. Als Resultat steht m. E. fest: 1. Die beiden Bücher im Cod. Bruc. sind die vom Verfasser des Buch II-III zitierten beiden Bücher des Jeû. 2. Infolgedessen müssen diese Bücher ein höheres Alter repräsentieren, zumal sie das Mysterienbuch der Sekte enthalten. 3. Buch IV der P. S. hat das Mysterienbuch als Quelle benutzt, zeigt zugleich gegenüber den Büchern I-III eine ältere Phase der Entwicklung, stimmt aber, abgesehen von den obersten Sphären, in der Kosmologie, besonders bei der Stellung des Jeû mit diesen überein. Deshalb muß Buch IV chronologisch zwischen die Bücher Jeû und Buch I-III gestellt werden. ${ }^{2}$

1 Hier hören wir auch von Jabraoth und seinen Archonten, die an das Lichtreich geglanbt haben und deswegen in einen reinen Luftort versetzt sind (vgl. dazu S. 95, 17; 259, 39 und Buch IV S. 263, 15 f. 23 f.

2 Ich halte es für höchst wahrscheinlich, daß Buch IV dem Verfasser von Buch I-III bekannt gewesen ist. 
Wenn wir Buch I-III auf die zweite Hälfte des 3. Jahrh. ${ }^{1}$ datieren, ${ }^{2}$ wird wohl Buch IV bereits der ersten Hälfte des 3. Jahrh. angehören, und dies gilt in noch höherem Grade von den Büchern Jeû, die ich ganz an den Anfang des 3. Jahrh. heranrücken möchte. Die ausgebildete Topographie der oberen Welt läßt es m. E. nicht zu, noch an das Ende des 2. Jahrh. hinabzugehen. ${ }^{3}$

Sehr bequem hat es sich Legge gemacht. Er geht von folgender ganz unbegründeten Voraussetzung aus: I have no hesitation in deciding that in this, the scribes followed the usual practice in legal matters and that the earliest document is that which comes first in the MS. (Introd. p. XXXII). Er weist dann noch besonders auf die Tatsache hin, daB in Buch I kein Zitat von dem Johannes-Ev. vorkomme, während Ptolemaeus und Heracleon, die um 170-200 n. Chr. die Häupter der Valentinianischen Schule waren, das Ev. genau kannten. - In der Tat hat der Verfasser das synoptische Material in höherem Maße verwendet, denn er gehörte nicht der spiritualistisch gestimmten gnostischen Schule der Alexandriner an, aber deswegen war ihm das Joh.-Ev. keine unbekannte Größe, wie eine Reihe Anspielungen zeigen, die Harnack zu diesem Buch I vermerkt hat. ${ }^{*}$ Und selbst wenn das Evangelium nicht direkt benutzt wäre, so steht wenigstens die Person des Apostels in hohem Ansehen. Denn Jesus begrüßt ihn mit den Worten in Buch I S. 49, 21: „Vortrefflich, Johannes, Du Jungfräulicher, der im Lichtreiche herrschen wird!" Diese Hochschätzung unterscheidet sich in nichts von derjenigen, die wir in den andern Büchern antreffen, indem S. 169, 2 f. (= Buch II) er ebenfalls der Jungfräuliche genannt wird und sein Thron zusammen mit dem der Maria Magdalena der nächste dem Throne Jesu in seinem Reiche

1 De Faye, Gnostiques et Gnosticisme. Étude critique des documents du Gnosticisme chrétien aux II e et III e siècles, Paris 1913, S. 254 tritt ebenfalls für diese späte Datierung ein.

2 Einzelne hier vorgetragene Anschauungen erinnern sehr an manichäische Vorstellungen. Sicherlich hat der Manichäismus die Reste der Gnostiker in sich aufgenommen.

3 Ganz entgegengesetzt ist das Urteil von Liechtenh., der das erste Buch Jeụ̂ noch eine Stufe tiefer stellt als die P. S., da es noch verworrener und noch mehr in heidnische Superstition verstrickt sei.

4 Vgl. 1. c. S. 27. 
sein wird, da diese beiden alle andern Jünger überragen. ${ }^{1}$ Die Figur des Johannes $\pi \alpha \varrho \vartheta \varepsilon ́ v o \varsigma$ weist auf eine spätere Zeit,

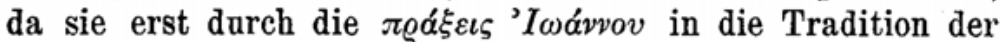
Kirche eingeführt ist. Damit ist das von Legge ins Treffen geführte Argument für das hohe Alter von Buch I ohne weiteres widerlegt. Und nicht besser steht es mit der Behauptung von der "successive degradation" der andern Bücher. Von Buch III heißt es Introd. p. XXXV: the third document resumes the descent of the slope of degradation with increased speed und p. XXXVI: with the fourth document, we seem to have reached the bottom of the slope. Legge kennt noch ein fünftes Dokument und mit diesem a still lower level is reached (Introd. p. XXXVII). ${ }^{2}$ Angesichts dieser unkritischen Haltung wird man sich nicht mehr über seine Datierungen p. XLVIII wundern:

To sum up, then, I believe that all the Documents in our text belong to the School of Valentinus. As to date, the First and the greatest part of the Second are probably taken from documents written by Valentinus himself, and therefore before A. D. 160, while the last part of the Second,

$1 \mathrm{Vgl}$. auch ,geliebter Bruder" S. 95, 37; 150, 5.

2 Legge-Horner haben Buch IV noch in zwei Abhandlungen zerlegt, und zwar soll das Ende der einen und der Anfang der zweiten auf den 8 Blättern in der Lücke S. 277 gestanden haben. Legge begründet seine These mit dem Hinweise, daß die Höhe der Strafen von seiten der Ar. chonten der Mitte in beiden Teilen ganz verschieden angegeben sei, so z. B. die Strafe eines Fluchers S. 267, 37 sich anf 133 Jahre und 9 Monate belaufe, dagegen S. 277, 28f. in jedem Stadium 6 Monate und 8 Tage; aber er hat dabei übersehen, $\mathrm{daB}$ an der zweiten Stelle jeder der Archonten des Weges der Mitte und jeder der 49 Dämonen die gleiche Strafe verhängt, so daß eine stattliche Anzahl Strafjahre herauskommt. Aber eine Tatsache, die Legge ganz übersehen hat, spricht für die Zasammengehörigkeit der beiden durch die Lücke getrennten Stücke. Petrus beschwert sich bekanntlich über das stetige Fragen der Frauen (S. 280, 9). Nun hat aber Maria nach der Lücke erst e in e Frage gestellt (S. 278, 17), ebenso Salome (S. 279,18). Selbst wenn Maria in der Lücke die beiden Fragen nach den Strafen eines Jähzornigen und eines Fluchers gestellt bätte, würde dies die Beschwerde des Petrus keineswegs rechtfertigen. Aber anders gestaltet sich die Sachlage, wenn in dem sogenannten ersten Stücke S. 266, 31 Maria mit der Prätension aufgetreten ist: „Nicht werde ich ablassen, Dich zu fragen. Zürne mir nicht, wenn ich nach allen Dingen frage." Deshalb war noch niemand von den Jüngern bis dato zu Worte gekommen. 
and the whole of the Third, Fourth, and Fifth, are by the degenerate successors of his school and are arranged in date order. These last may be of any date between A. D. 245 and 388 , when we last hear of the Valentinians as an organised sect, and some parts of them may not improbably be later still.

Das führt mich zu dem letzten Teil meiner Untersuchung, zu der Frage nach der Verfasserschaft der im Cod. Askewianus enthaltenen Schriften.

Legge hat die alte These von dem valentinianischen Ursprang, sei es des Valentin selbst, sei es seiner Anhänger, wieder aufs Tapet gebracht. Woide war als erster für Valentin eingetreten und seiner Meinung haben sich Gelehrte wie Jablonski, La Croze, Dulaurier, Schwartze, Renan, Revillout, Amélineau, Usener angeschlossen. Man verweist dabei häufig auf Tertullian, adv. Val. c. 2: Porro facies dei expectetur in simplicitate quaerendi ut docet Sophia, non quidem Valentini, sed Salomonis. Man erschließt aus dieser Stelle ein Werk des Valentin, betitelt $\Sigma o p i ́ \alpha$, aber diese Annahme ist höchst zweifelhaft (vgl. Zahn, G. K. II, 121, Anm. 2). Was sonst noch von verschiedenen Seiten für den Valentinianischen Ursprung ins Treffen geführt wird, ist ohne jede feste Substantiierung. Wenn unsere Pistis Sophia oder Teile davon wirklich dem Valentin oder dessen Schule zuzuschreiben seien, müßte man sich schier wundern, wie die Vertreter der Großkirche eine so große Gefahr von seiten dieser Kreise für den Bestand des Christentums zu befürchten glaubten, denn die verworrenen Phantasien in dem System lassen auf keinen von philosophischen und theosophischen Ideen erfüllten Geist schließen. Von den tiefgründigen Spekulationen der Valentinianer, die uns aus den Exzerpten der Kirchenväter entgegentreten, findet sich keine Spur.

Von ganz andern Voraussetzungen aus hat Koestlin das System der P. S. einer besonderen Untersuchung gewürdigt ${ }^{1}$ und ist za dem Resultat gekommen, daB der Verfasser in ophitischen Kreisen zu suchen sei. Seinen Spuren sind gefolgt Baur, Lipsius, Jacobi, Harnack, ${ }^{2}$ Mead, Liechtenhan, Bousset, de Faye u. A. In meinen Untersuchungen

1 Theol. Jahrb., herausg. von Baur und Zeller, Bd. 13 (1854), S. 1-104 und $137-196$.

2 1. c., S. $103 \mathrm{ff}$. 
über die gnostischen Schriften im Cod. Bruc. ${ }^{1}$ habe ich diese Untersuchungen an der Hand der neuen Quellen weitergeführt. Ich war dabei von zwei charakteristischen mythologischen Aeonenfiguren ausgegangen, nämlich von der Barbelo und dem Jaldabaoth.

Die Barbelo (Barbelos) hat ihren Wohnsitz wahrscheinlich im 13. Aeon, da sie die große Kraft des unsichtbaren Gottes genannt wird (S. 273, 9) und aus ihr die 24 Unsichtbaren emaniert sind (S. 34, 32), darum die Pistis Sophia ihre Tochter genannt wird (S. 264, 14). Nach Jeû II befindet sie sich mit dem unsichtbaren Gott und dem Ungezengten im 12. Aeon und beherrscht die großen Archonten der Aeonen ${ }^{2}$ (S. 225, 39; 226, 5).

Eine gewisse $B \alpha \varrho \beta \eta \lambda \omega, B \alpha \varrho \beta \eta \lambda \omega \vartheta$ erwähnen die Ketzerbestreiter bei folgenden Sekten:

1. bei den Ophiten. Epiph. h. 37, 3,

2. bei den Nikolaiten. Epiph. h. 25, 2,

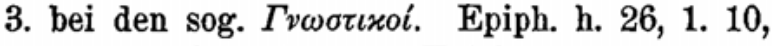

4. bei den Simonianern. Epiph. h. 21, 2,

5. bei den Barbelo-Gnostikern. Iren. adv. haer. I, 29,1. 4; $30,3$.

Zuweilen führt die Barbelo den Namen Sophia-Prunikos; sie gilt allgemein als die Mutter des Weltschöpfers Jaldabaoth oder des Judengottes Sabaoth.

Jaldabaoth ist nach Buch I-IV der Archon im Chaos mit Löwengesicht, in dessen Feuer-, Pech- und Schwefelmeeren die Sünder furchtbar bestraft werden (S. 33, 20; $188,10 ; 278,30 ; 279,32 ; 280,25 ; 281,19 ; 282,11.25)$. Nach Jeû II (S. 322, 32) befindet er sich im dritten Aeon der Archontenwelt. Die Ketzerbestreiter erwäknen ihn bei folgenden Sekten:

1. bei den Ophiten. Epiph. h. 37, 3; Theod. h. fab. I, 14; Pseudo-Tert. c. 47; Philastr. c. 1,

2. bei den Nikolaiten. Epiph. h. 25, 2. 3; Philastr. c. 33,

1 TU VIII (1892), S. $559 \mathrm{ff}$.

2 Das kann nicht ursprünglich sein, denn nach Jeû II S. 226, $23 \mathrm{f}$. befinden sich im 13. Aeon der große Unsichtbare, der große jungfräuliche Geist und die 24 Emanationen des unsichtbaren Gottes. Es sieht wie eine Dablette zu dem 12. Aeon aus und ist die Barbelo mit dem jungfräulichen Geist zu identifizieren. 


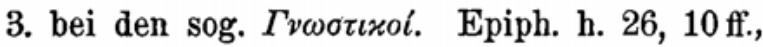

4. bei den Severianern. Epiph. h. 45, 1,

5. bei den Barbelo-Gnostikern. Iren. I, 30, $1 \mathrm{ff}$.,

6. bei den Ophianoi (Ophiten). Celsus bei Orig. c. Cels.VI, 31 .

Bei diesen Sekten gilt Jaldabaoth, wie gesagt, als Sohn der Barbelo resp. der Sophia-Prunikos; er hat seinen Wohnsitz im 7. Himmel und ist zugleich der Weltschöpfer. Wie man sieht, ist er im Laufe der Zeit von dieser Höhe als Weltschöpfer zum Archon des Chaos herabdegradiert worden. Barbelo und Jaldabaoth müssen bereits bei Gründung der Sekte eine besondere Rolle im Gott-Welt-Proze $B$ gespielt haben, da sie schon Irenaeus und der Heide Celsus um 180 n. Chr. erwähnen. Irenaeus hat für diese Gnostiker nur die allgemeine Bezeichnung multitudo Gnosticorum Barbelo. Das war eine mannigfaltig gespaltene Gruppe unter den gnostischen Sekten, die der älteste Ketzerbestreiter Justin in seinem $\sigma v ́ v \tau \alpha \gamma \mu \alpha$ in folgender Reihenfolge aufgeführt hatte: 1. Nicolaiten, 2. Ophiten, 3. Kainiten, 4. Sethianer. Epiphanius hat sie in seiner Darstellung h. 25. 26. 37. 38. 39. 40. $45 \mathrm{um}$ zahlreiche Namen vermehrt. Diese Sekten sind aber nicht auf dem Boden Ägyptens, sondern Syriens entstanden, haben vielmehr sich von hier nach Ägypten verpflanzt und daselbst ein langes Leben bis über die Zeit des Epiphanius gefristet. Fs waren in erster Linie Kultgenossenschaften, die abseits von den Schulen der Valentinianer und Basilidianer sich entwickelt hatten. Und eben weil sie von Syrien eingewandert waren, haben sie auch mannigfach aramäisch oder hebräisch klingende Namen für ihre Aeonenfiguren mitgebracht, von denen wir keine Spur in den Systemen der großen Schulhäupter finden. Auch war es natürlich, daB diese barbarischen Namen auf griechisch-ägyptischem Boden unverstanden blieben und bald alteriert wurden, ${ }^{1}$ weshalb wir schwerlich ihre ursprüngliche Bedeutung ergründen können. Im Laufe der geschichtlichen Entwicklung haben diese Sekten sich eine ungemein umfang-

1 Von diesem Standpunkte kann ich der Meinung von Burkitt l. c. S. 279 nicht beipflichten: the nomenclature does not suggest any real acquaintance with Semitic languages or Semitic alphabets, but only a superstitious veneration for Hebrew names found in the Greek versions of the Old Testament, eked ont by scraps of illdigested bits of Hebrew supplied (not doubt) by Jews. 
reiche Offenbarungsliteratur zugelegt, die Harnack I. c. S. 107 zusammengestellt hat. Dabei stoBen wir auf ein Evangelium des Philippus (Epiph. h. 263) und auf die "großen“ und „kleinen Fragen der Maria“ (Epiph. h. 268). Nun erinnern wir uns, daß Philippus in der P. S. für Buch I-III als der beauftragte Schreiber der Reden und Taten Jesu gilt. Aber mit diesem Evangelium können wir unser Werk nicht in Verbindung bringen, da jenes libertinistischen Anschauungen Vorschub leistete. Nur das eine können wir daraus entnehmen, $\mathrm{da} B$ der Name des Apostels Philippus bei diesen Gnostikern für ihre Offenbarungsliteratur benutzt worden ist, und dab unser Verfasser höchstwahrscheinlich den Mythus der Sophia in einem dem Philippus zugeschriebenen Werke gelesen hat.

Ganz einzigartig ist die Stellung der Maria, d. h. der Maria Magdalena in allen 4 Büchern der P. S. Sie ist es, die als erste Rednerin auftritt und, nachdem sie eine Stande lang in die Luft gestarrt, ${ }^{1}$ den Herrn bittet, offen reden zu dürfen. Der Herr begrüßt sie mit folgenden Worten: „Maria, Du Selige, welche ich in allen Mysterien derer von der Höhe vollenden werde, rede offen, $\mathrm{Du}$, deren Verstand mehr als alle Deine Brüder auf das Himmelreich gerichtet ist" (S. 18, 30f.), und gleich darauf heißt es: „Vortrefflich Maria! Du bist selig vor allen Weibern, die auf Erden, weil Du Fülle aller Füllen und Vollendung aller Vollendungen sein wirst" (S. 20, 15f.). ${ }^{2}$ Unablässig drängt sie sich vor, so daß endlich dem Petrus die Geduld reißt, und er in die Worte ausbricht: „Mein Herr, wir werden dieses Weib nicht ertragen können, da sie uns die Gelegenheit nimmt und sie niemand von uns hat reden lassen, sondern vielmals redet" (S. 42, $10 \mathrm{f}$.). Maria Magdalena ist es auch, welche nach der Beendigung der P. S.-Episode den Reigen der Fragen an Jesus S. 135, $17 \mathrm{ff}$. eröffnet und dabei die übrigen Jünger (39 von 46 Fragen) ganz in den Hintergrund drängt. Hier zittert noch der Angriff des Petrus nach, denn Maria möchte, weil ihr Verstand allezeit verständig, stets vortreten, aber sie fürchtet sich, wie sie sich ausdrückt, vor Petrus, weil er ihr drohe und das weibliche Geschlecht hasse (S. 119, 14f.). Auch in Buch IV ist

1 Das ist die Vorbereitung anf die Vision.

2 Vgl. auch die Zusammenstellung TU VIII, S. $452 \mathrm{f}$. 
dieselbe Situation, denn S. 266, 31 f. verkündet Maria: „Nicht werde ich ablassen, Dich zu fragen. Zürne mir nicht, wenn ich nach allen Dingen frage." Wiederum tritt ihr Petrus entgegen: „Mein Herr, mögen die Frauen zu fragen aufhören, damit auch wir fragen", und Jesus muß ihren Redestrom dämpfen: „Gestattet euren männlichen Brüdern, daß auch sie fragen." - Eine derartige feindselige Haltung des Petrus zu Maria Magdalena in beiden verschiedenen Stücken kann m. E. nur auf eine gemeinsame Quelle zurückgehen, sollte der Verfasser von Buch I-III nicht direkt von Buch IV abhängig sein.

$\mathrm{Zu}$ unserer Überraschung finden wir in dem noch unpublizierten koptisch-gnostischen Papyrus Berolinensis der ägyptischen Papyrusabteilung an erster Stelle eine Abhand-

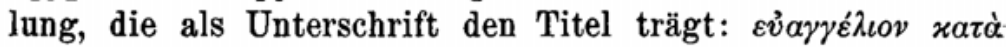

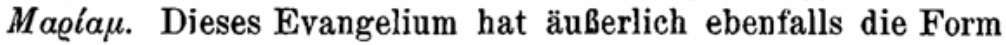
von Unterredungen des Sotêr ${ }^{1}$ mit den Jüngern. Der Herr befiehlt, das Evangelium vom Reiche zu predigen und geht von ihnen. Darüber sind die. Jünger betrübt, denn wie könnten sie das Evangelium vom Reiche des Menschensohnes predigen, wenn man des Herrn selbst nicht geschont hätte. Da tröstet Maria die Tranernden mit dem Hinweis, daß des. Herrn Gnade mit ihnen sein würde und sie beschirmen, vielmehr sollten sie seine Herrlichkeit preisen. Infolgedessen wendet sie den Verstand der Jünger zum Guten hin und sie beginnen betreffs der Worte des Erlösers zu diskutieren. Da spricht Petrus folgendes zu Maria: „Schwester, wir wissen, daB der Herr dich liebte mehr als die übrigen Frauen. Sage uns die Worte des Erlösers, deren du dich erinnerst, diese, die du kennst, nicht wir, noch haben wir sie gehört." Maria erklärt sich bereit, das Verborgene ihnen zu verkündigen, und trägt den Inhalt eines Traumgesichtes vor, dessen sie vom Erlöser teilhaft geworden war. Nach Beendigung dieses Vortrages spricht Andreas zu den Brüdern: „Saget, was sagt ihr inbetreff dessen, was sie gesagt hat? Ich nämlich glaube nicht, da $B$ der Erlöser dieses gesagt hat, vielleicht sind diese Lehren andere Gedanken." Da nimmt Petrus das Wort: „Hat er (sc. der Erlöser) geredet mit einem lästernden Weibe zu uns? Offenbar nicht. Sollen wir selbst umkehren und

1 Leider ist der Anfang verloren, aber es scheint die Situation die zu sein, daß der Himmlische den Jüngern sich offenbart. 
auf sie hören? Hat er dich vor uns auserwählt?" Maria spricht weinend zu Petrus: „Denkst du, daB ich von selbst es ausersonnen habe in meinem Verstande oder dab ich den Erlöser belüge?" Jetzt springt Levi für sie ein und weist Petrus mit den Worten in die Schranken: „Petrus, von jeher bist du ein Heftiger. Jetzt sehe ich dich wetteifernd gegen das Weib wie die Widersacher. Wenn der Erlöser aber sie würdig gemacht hat, wer bist selbst, um sie ganz und gar zu verwerfen? Weil der Erlöser sie genau kennt, deswegen hat er sie geliebt mehr als uns alle. Vielmehr mögen wir uns schämen und anziehen den vollkommenen Menschen und uns zubereiten, wie er uns befohlen hat, und predigen das Evangelium, indem wir nicht anfertigen andere Gebote noch andere Gesetze neben dem, was der Erlöser gesagt hat."

Diese Episode ist von grundlegender Bedeutung für die geschichtliche Entwicklung der Sekte. Denn das „Evangelium der Maria" gehört unzweifelhaft zu den ältesten Dokumenten des Gnostizismus und ist höchstwahrscheinlich ebenso wie das

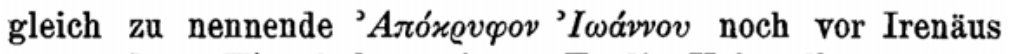
entstanden. Hier haben wir m. E. die Keimzelle vor uns, aus der die spätere Hochschätzung der Maria Magdalena sich entwickelt oder forttradiert hat. Maria gilt als das besondere Offenbarungsorgan des Erlösers, und man begreift von hier ihre überschwengliche Lobpreisung aus dem Munde Jesu in der P. S. Man begreift ferner, wie ein gnostischer Autor sein Werk mit "großen" resp. "kleinen Fragen der Maria“ betiteln konnte, denn er stand unter dem Zwange einer alten Tradition und glaubte sein Elaborat nicht besser seinen gnostischen Brüdern empfehlen zu können, als daß er es anter dem Namen der Maria verbreitete. Selbst dem Celsus ist diese Hochschätzung der Maria in der gnostischen Literatur nicht verborgen geblieben, wenn er Orig. c. Cels. V, 62 be-

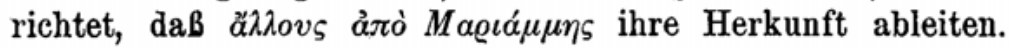
Auf der andern Seite wird uns klar, wie von Anfang an eine heftige Opposition gegen die Weiblichkeit als besondere Trägerin des gnostischen $\pi v \varepsilon \tilde{v} \mu \alpha$ eingesetzt hat, als deren Wortführer Petrus hingestellt wird. Von hier aus hat sich diese Opposition bis in die Zeit der P. S. noch literarisch fortgepflanzt.

Und noch ein anderes Offenbarungsorgan neben der Maria Magdalena hatten wir in der P. S. kennen gelernt, das war Schmidt: Pistis Sophia. 
der Apostel Johannes. ${ }^{1}$ Nun finden wir in demselben Cod.

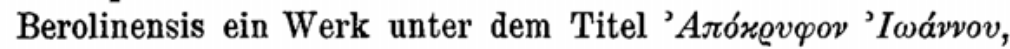
das ausschließlich Offenbarungen des himmlischen Jesus an Johannes enthält. Dieses Werk ist mit jenem Werke identisch, das Irenäus in Adv. haer. I, 29 in seinem ersten Teile exzerpiert hat. ${ }^{2}$ Er weist diese Schrift der multitudo Gnosticorum Barbelo zu und gibt in c. 30 einen weiteren Auszug aus einer Originalschrift, die einer verwandten gnostischen Sekte angehört. In diesem Apokryphon des Johannes wird die Kosmologie und Anthropologie ausführlich behandelt, and lernen wir auch die Barbelo und ihren Sohn Jaldabaoth

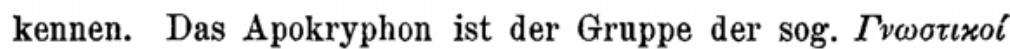
zuzurechnen, speziell dem Kreise der Sethianer, ${ }^{3}$ da Seth über das zweite Licht gesetzt ist und der Same des Seth, d. h. die Seelen der Heiligen, die ihre Vollendung erkannt haben, sich im dritten Aeon befindet. Zu dieser Sekte der Sethianer hatte ich bereits das sog. "unbekannte altgnostische Werk" gestellt. ${ }^{*}$ Mit den Sethianern war Epiphanius nach h. 39, 1 in Ägypten persönlich zusammengetroffen. Diese Sethianer sind aber nicht zu verwechseln mit jenen lasciven Gnostikern in h. 26, mit denen Epiphanius ebenfalls in Ägypten in persönliche Berührung gekommen war. Wir haben ja oben gesehen, mit welcher Entrüstung die Gnostiker der P. S. diese Lascivität ihrer verirrten Brüder verdammt haben und von ihnen weit abgerückt sind, ${ }^{5}$ da sie von einem hohen sittlichen

1 In Buch III ist er neben Maria Magd. fast ausschließlich der Wortführer.

2 Sitzungsb. d. Königl. Preuß. Akad. d. Wissensch. 1896, S. $839 \mathrm{ff}$. and Irenäus und seine Quelle in Adv. haer. I, 29 (Philotesia, Paul Kleinert zum LXX. Geburtstage dargebracht, S. $317 \mathrm{ff}$.).

3 Theodoret h. f. I, 14 führt das Exzerpt aus Irenäus mit den Worten ein: Oi $\delta \dot{\varepsilon} \Sigma \eta \eta \vartheta$

4 Kopt.-gnost. Schriften I, S. $335 \mathrm{ff}$; vgl. TU VIII, $645 \mathrm{ff}$.

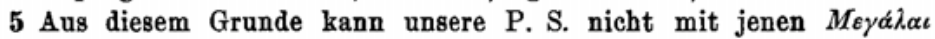

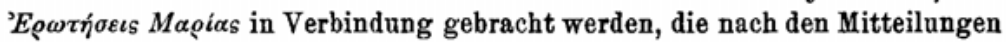
des Epiphanius libertinistischen Ideen huldigten. - Nun hat man aber die P.S. mit den ebenfalls von Epiph. h. 26, 8 genannten ${ }_{n}$ kleinen Fragen der Maria ${ }^{\prime}$ in Verbindung gebracht. Schon Renan, Marc Aurel p. 120, Anm. 3 hat anf diese hingewiesen, und unabhängig von ihm hat Harnack, TU VII, 2 S. $107 \mathrm{f}$. diese These vertreten (vgl. auch Geschichte der altchristl. Lit. I, 172 und Chronologie II, 194). Während Liechtenhan l. c. 240 f. verschiedene Einwände erhob, ist de Faye 1. c. S. 266, Anm. 2 lebhaft für Harnack eingetreten. Auch ich neigte mich früher dieser Ansicht za (TU VIII, 597), glanbte sie 
Ideal getragen wurden, das mit der christlichen Ethik unbedingt auf eine Linie gestellt werden kann. Denn wenn sie ihren Adepten bei der Taufe die Verpflichtung auferlegten, „nicht falsch zu schwören noch überhaupt zu schwören, nicht zu huren, nicht zu ehebrechen, nicht zu stehlen, nicht irgend etwas zu begehren, nicht Silber noch Gold zu lieben, nicht den Namen der Archonten noch den Namen ihrer Engel um irgendeine Sache anzurufen, nicht zu rauben, nicht zu fluchen, nicht fälschlich zu verleumden noch zu beschuldigen, sondern ihr Ja sei Ja und ihr Nein Nein, mit einem Wort, sie sollen die guten Gebote vollführen" (Jeû II, S. 305, 26 ff.), so legt dies ein beredtes Zeugnis für ihre christliche Haltung ab.

So schließt sich ein einziger Ring um die gesamte koptischgnostische Literatur, soweit sie uns in den drei Codices, dem Cod. Askewianus, Brucianus und Berolinensis, überliefert ist. Sämtliche Schriften von der ältesten bis zur jüngsten Epoche stehen miteinander in engster Verbindung; sie entstammen alle der weitverbreiteten Gruppe der $\Gamma \nu \omega \sigma \tau \varkappa o l^{1}{ }^{1}$ Auf einen Spezialnamen wie Sethianer braucht man sich nicht zu versteifen, da die Grenzen zwischen den einzelnen Gliedern sehr fließende waren, und, wie man aus den Mitteilungen des Epiphanius ersieht, in diesen Sekten ein wechselseitiger Austausch nicht nur der Ideen, sondern auch der einzelnen Schriften stattgefunden hat. Die Valentin-Hypothese freilich - und das, hoffe ich, wird als das sichere Resultat meiner Untersuchungen über die koptisch-gnostische Literatur allgemein anerkannt werden - ist damit endgültig erledigt.

aber nicht weiter vertreten za dürfen, da 1. diese Identifikation nur für Buch I-III gelten könnte und 2. auch dieses wieder nur für Buch II, S. 135, 16 ff. und Buch III, da die P.S.-Episode m. E. keinen Bestandteil der ${ }_{n}$ kleinen Fragen der Maria " gebildet haben kann und 3. die in dem Codex vorkommenden Titel nicht ganz beiseite geschoben werden dürfen. Deswegen brauchen die „kleinen Fragen" keinen obscönen Inhalt gehabt zu haben, da Epiphanius dies nicht ausdrücklich von ihnen bezengt. Die Analogie liegt m. E. in der übereinstimmeuden Hochschätzung der Maria Magdalena und in der von den gnostischen Autoren der P. S. beliebten Literaturform der "Fragen“. Es wäre aber nicht ausgeschlossen, $\mathrm{daB}$ von dem Autor von Buch I-III Material aus jenem Buche entnommen wäre.

1 Diese Gnostiker haben ihre heilige Literatur bis in die letzte Zeit ihrer Existenz tradiert und sie einer Übersetzung aus dem Griechischen ins Koptische gewürdigt, als die gnostische Bewegung auch in der ein. heimischen Bevölkerung Ägyptens festen Fuß gefaßt hatte. 